
\title{
25 Research Suare \\ Early Gastric Cancer Lymph Node Metastasis Model and Prognostic Survival Prediction Model in Western Population
}

Huakai Tian

Nanchang University Second Affiliated Hospital

Zuo Zhang

Nanchang University Second Affiliated Hospital

Zitao Liu

Nanchang University Second Affiliated Hospital

Cegui Hu

Nanchang University Second Affiliated Hospital

Jiang Liu

Nanchang University Second Affiliated Hospital

Tian Xu

Nanchang University Second Affiliated Hospital

Zhen Zong ( $\square$ ndefy16133@ncu.edu.cn )

Nanchang University Second Affiliated Hospital

Research

Keywords: Early gastric cancer, lymph node metastasis, survival prognosis, endoscopic mucosal resection, Predictive model

Posted Date: November 23rd, 2020

DOI: https://doi.org/10.21203/rs.3.rs-112129/v1

License: (a) (1) This work is licensed under a Creative Commons Attribution 4.0 International License. Read Full License 


\section{Abstract}

\section{Objective}

This study analyzed the characteristics of early gastric cancer lymph node metastasis and survival prognosis after surgical resection in western population, and established a predictive model.

\section{Methods}

Patients with stage T1a and T1b gastric cancer from 2010 to 2015 were screened from the surveillance, epidemiology and final outcome databases. Patients with multiple in situ tumors, distant metastases, and incomplete data were excluded. The risk factors for lymph node metastasis in early gastric cancer were analyzed by binary logistic regression and the chi-square test. Multivariate Cox analysis and the Kaplan-Meier test were used to evaluate the prognostic factors and survival rates of patients with early gastric cancer after surgical resection. The prediction model of lymph node metastasis and survival rate of early gastric cancer was established and verified by $\mathrm{R}$ software.

\section{Results}

In 2294 patients, the lymph node metastasis rate was 14.5\% (333/2294). Binary logistic multivariate regression analysis showed that tumor size $(>2 \mathrm{~cm})$, tumor grade (III/IV), and stage T1b were risk factors for lymph node metastasis of early gastric cancer. Area under the curve (AUC) is 0.782.A predictive model was developed based on risk factors, and the model $\mathrm{C}$ index was 0.771 , indicating that the model has good predictive ability. In addition, survival analysis of 2294 patients showed that the 5-year OS and CSS (75.4\% and $88.7 \%$ ) in patients without EGC were significantly higher than those with lymph node metastasis $(64.3 \%$ and $72.8 \%)(P<0.05)$. Multivariate COX analysis showed that age, sex, race, tumor size, submucosal invasion and lymph node metastasis were independent factors influencing the prognosis of early gastric cancer. A cancer-specific survival (CSS) prediction model was constructed based on prognostic risk factors. The 3-year area under the CSS curve (AUC) was 0.706 , and the 5-year area under the CSS curve (AUC) was 0.710 . The prediction model is more consistent with the actual situation.

\section{Conclusions}

We established a reliable prediction model for lymph node metastasis of early gastric cancer and a prognostic model for early gastric cancer, which provided a good basis for clinical treatment decision.

\section{Introduction}

Gastric cancer is one of the most common malignant tumors, ranking fifth in morbidity and third in mortality worldwide[1, 2]. Early gastric cancer is defined as lesions confined to the mucosa and/or submucosa, regardless of size or lymph node metastasis[3]. Data show that the incidence of early gastric cancer in Western countries is lower than in Asian countries[4, 5]. 
The treatment of early gastric cancer is being gradually replaced by more minimally invasive methods such as endoscopic mucosectomy and endoscopic submucosal dissection[6, 7]. Compared with surgical gastrectomy, endoscopic treatment has the advantages of shorter operation time, less trauma, faster recovery and fewer complications[8-10]. In western countries, endoscopic mucosectomy and endoscopic submucosal dissection have been increasingly used in the treatment of stage T1 colorectal cancer, but the treatment of early gastric cancer still mostly involves radical surgical resection[ 7,11$]$. The main risk of minimally invasive endoscopic treatment is lymph node metastasis, which seriously affects the prognosis of patients, and lymph node dissection is required for patients with lymph node metastasis[12, 13]. The lymph node metastasis rate of early gastric cancer is rarely reported in western countries but is $14.4 \%-22 \%[7,14]$. Therefore, most patients with early gastric cancer in western populations do not have lymph node metastasis, and surgery in these patients would lead to overtreatment. Methods to reduce unnecessary radical surgery and to identify patients with early gastric cancer who are at high risk of lymph node metastasis are worth exploring.

According to the guidelines of the Japanese Gastric Cancer Association (JGCA), well-differentiated, nonulcerated intramucosal carcinoma with a diameter of less than $2 \mathrm{~cm}$ is the absolute indication for endoscopic therapy, while ulcerated and undifferentiated submucosal carcinomas are the expanded indications[15]. There is no clear standard for endoscopic therapy for patients with early gastric cancer in western countries. In addition, there is insufficient evidence for the prognosis of survival in patients with early gastric cancer after surgical resection in the western population. It is feasible to explore the risk factors and survival prognosis of lymph node metastasis of early gastric cancer by analyzing the relationships between the clinical features of patients with early gastric cancer after surgical resection and the risk and survival rates of lymph node metastasis. Therefore, a large national registration database (surveillance, epidemiology and end results [SEER] database) and data on the surgical removal of the specimen and the survival prognosis were used to explore risk factors of early gastric cancer lymph node metastasis and prognosis of survival to establish effective treatment strategies for western populations with early gastric cancer.

\section{Methods}

The data comes from the SEER database of the National Cancer Institute, which covers basic information for approximately $28 \%$ of US cases. Because the information in this database is publicly used, we have authorized the database (account number: 12846-Nov2019), so the patient's informed consent is not required.This research has passed the ethical review of the research institution and provided proof. From the database, we mainly collected relevant information, including general characteristics, clinical tumor characteristics, pathological characteristics, treatment methods, survival and prognosis. Inclusion criteria: 1. Postoperative diagnosis of early gastric cancer (T1a and T1b); 2 . Complete survival information. Exclusion criteria: 1 . Suffered from multiple tumors in situ; 2. Distant metastasis; 3 . Incomplete tumor staging; 4. Incomplete information. 
Tumor site, grade, and histology were coded according to the International Classification of Diseases for Oncology, version 3. Tumor stage was coded according to the AJCC tumor-node-metastasis staging system, $7^{\text {th }}$ edition[16].

Gastric cancer patients were diagnosed from 2010 to 2015 . Ages were divided into $<50$ years old, 50-60 years old, 60-70 years old, 70-80 years old, and $>80$ years old. Race was divided into white, black, and other (American Indian/AK Native, Asian/Pacific Islander). Tumor size was divided into $<2 \mathrm{~cm}, 2-5 \mathrm{~cm},>5$ $\mathrm{cm}$ and unknown. Tumor grade was divided into Grade I, Grade II, Grade III, Grade IV and unknown. Tissue classification included adenocarcinoma, signet ring cell carcinoma and others. The depth of tumor invasion included $\mathrm{T} 1 \mathrm{a}$ and $\mathrm{T} 1 \mathrm{~b}$. The location of the primary tumor was divided into cardia, fundus, gastric body, antrum, pylorus, lesser curvature, greater curvature, and overlapping/NOS.

In this study, the incidence of lymph node metastasis, risk factors, overall survival rate (OS) and tumorspecific survival rate (CSS) of early gastric cancer were mainly observed,and construct the prediction model.

\section{Statistical analysis}

For descriptive statistics, the chi-square test or Fisher's exact probability method were used to compare categorical variables. Binary logistic regression was used to analyze the risk factors for lymph node metastasis of early gastric cancer. The results are represented by odds ratios (ORs) and $95 \%$ confidence intervals (Cls). Meanwhile, a forest map was plotted using GraphPad Prism 2019b. For survival analysis, the multivariate Cox test was used to analyze OS and CSS, and the results are presented as odds ratios (ORs) and $95 \%$ confidence intervals (Cls).

Kaplan-Meier curves were used to calculate 3- and 5-year OS and CSS rates, and the log-rank test was used to identify significant differences across groups. The follow-up times for all the analyses were from the date of diagnosis until the date of death, last contact, or the end of the study period. If the patient was alive, the patient was censored at the date of last contact. To evaluate CSS, patients who died due to colorectal cancer were identified using the cause of death specified on the death certificate. Patients who died from causes unrelated to their colorectal cancer diagnosis were censored at their date of death.The prediction model of lymph node metastasis and CSS was established and verified by R software.

Statistical analyses were performed using IBM SPSS software for Windows, version 23.0 (IBM Corporation, Armonk, NY, USA). A P value of $<0.05$ was considered statistically significant.

\section{Results}

\section{Single-factor analysis of lymph node metastasis in EGC patients}

According to our inclusion and exclusion criteria, 2,294 surgically resected patients were ultimately included (Figure 1). Among them, there were 1,961 (85.5\%) patients with negative lymph nodes and 333 
(14.5\%) patients with positive lymph nodes. The total lymph node metastasis rate was $14.5 \%$. Single factor analysis showed that race, tumor size, tumor grade, tumor type, tumor site, and tumor infiltration depth were associated with lymph node metastasis, and the results have statistical significance $(P<0.05)$ (Table 1).

\section{Multivariate analysis of lymph node metastasis}

To more accurately analyze the risk factors for lymph node metastasis in patients, we conducted binary logistic regression analysis on factors $\mathrm{P}<0.1$ (age, race, tumor size, tumor grade, tumor tissue type, tumor site, and infiltration depth) and drew a forest map. The results showed that tumor size, grade and infiltration depth were independent risk factors for lymph node metastasis in patients with early gastric cancer (Figure 2). The lymph node metastasis rates of patients with tumor sizes of 2-5 cm (OR 1.766, $95 \% \mathrm{Cl} 1.330-2.343, \mathrm{P}<0.001)$ and $>5 \mathrm{~cm}(\mathrm{OR} 4.308,95 \% \mathrm{Cl} 2.738-6.779, \mathrm{P}<0.001)$ were significantly higher than that of patients with tumor size $<2 \mathrm{~cm}$. The lymph node metastasis rates of patients with grade II (OR 2.273, 95\% Cl 1.295-3.991, P<0.05) and III/IV (OR 3.957, 95\% Cl 2.263-6.919, P<0.001) were higher than that of patients with grade I early gastric cancer. The lymph node metastasis rate in patients with stage T1b (OR 4.108, 95\% Cl 2.994-5.637, $\mathrm{P}<0.001)$ was significantly higher than that in patients with stage T1a (Table 2).

\section{Construction and verification of Nomogram}

A nomogram for predicting LNM was established based on the following three independent risk factors (Figure 3): tumor size, tumor grade, and depth of invasion. The calibration curve shows that the nomogram is well calibrated, with a $\mathrm{C}$ index of 0.771 (Figure 4). When predicting risk factors for LNM, the area under the ROC curve was 0.782 (Figure 5). The establishment of nomogram is helpful to predict LNM.

\section{Survival analysis of patients with early gastric cancer}

In patients with early gastric cancer, we conducted a multivariate Cox risk analysis on the OS and CSS of the patients. The results found that lymph node metastasis is the most powerful risk factor for the increase in mortality in patients with early gastric cancer. Patients with lymph node metastasis had poor OS (OR 1.538, 95\% Cl 1.214-1.949, P<0.001) and CSS (OR 2.000, 95\% Cl 1.489-2.685, P<0.001). In addition, age, race, sex, tumor size, and depth of tumor invasion were significantly associated with survival. (Table 3 ).

Next, the presence or absence of lymph node metastasis and tumor infiltration depth were analyzed by Kaplan-Meier test, and the 3- and 5-year OS and CSS were calculated. According to the results shown in Figure 3B and Figure 4B, the 3- and 5-year OS rates of EGC patients without lymph node metastasis (84.1\% and $75.4 \%$ ) were significantly higher than those with lymph node metastasis $(72.0 \%$ and $64.3 \%)$ $(P<0.05)$. The 3 - and 5-year OS rates of T1a patients $(86.4 \%$ and $79.6 \%)$ were significantly higher than 
those of T1b patients $(78.3 \%$ and $68.0 \%)(P<0.05)$. Similar results were observed for CSS rate (Figure $3 \mathrm{~A}$ and Figure 4A).

\section{Construction and validation of CSS prognostic normogram}

CSS prognostic prediction models were constructed based on risk factors affecting prognosis of early gastric cancer and validated internally (Figure 8). The 3-year and 5-year CSS prognostic calibration curves show that the prediction model is well calibrated, and the model is more consistent with the actual situation (Figure 9). The area under 3-year and 5-year CSS prognostic ROX curves were 0.706 and 0.710 , respectively (Figure 10), indicating that prognostic risk factors for early gastric cancer can better reflect the 3-year and 5-year prognostic survival of patients.

\section{Discussion}

The incidence of EGC in western countries is much lower than in Asian countries. In Asian countries, the number of new cases of early gastric cancer accounts for approximately $50 \%$ of the total[17]. Asian countries, especially Japan, have conducted a large number of studies on the treatment of EGC and formulated relevant treatment standards. Endoscopic mucosectomy and endoscopic submucosal dissection have been widely used in the treatment of EGC and have been established as the standard methods of endoscopic resection of early upper gastrointestinal tumors in Japan[18]. Compared with Asian countries, the progress of endoscopic treatment technology in western countries is relatively slow, and the treatment of EGC is still based on radical surgical resection[19,20]. Therefore, it is not clear whether EGC is suitable for endoscopic therapy in western populations, especially for patients who are candidates for endoscopic therapy. In addition, at present, the sensitivity and specificity of endoscopic ultrasonography and CT and other imaging examinations for the determination of EGC lymph node metastasis are not ideal[21,22], and the preoperative prediction of lymph node metastasis is not reliable. Analyzing the relationship between the clinicopathological features of EGC patients and lymph node metastasis can be used as a supplementary means for the preoperative diagnosis of lymph node metastasis to more clearly define the treatment of EGC patients.

Lymph node metastasis is a major factor in the endoscopic treatment and prognosis of EGC patients[23, 24]. In this study, we found that the lymph node metastasis rate of stage $T 1$ gastric cancer after surgical resection was $14.5 \%$ (333/2294). Studies from Asia have shown that the rate of lymph node metastasis in EGC is $10-25.3 \%[12,25]$, which is consistent with our findings. Patients less than 50 years old are more likely to develop LNM than patients in other age groups. When the subgroups were stratified by tumor location, the incidence of gastric pyloric tumor LNM was the highest. This phenomenon may be due to the multiple sets of lymph nodes near the pylorus. The risk factors for lymph node metastasis in western countries are similar to those in Asian countries. However, the ethnicities of Asian populations are relatively homogeneous. In western populations, the lymph node metastasis rate and survival prognosis are different between different races. The potential risk of lymph node metastasis in white EGC patients is lower than those of blacks or American Indians and Asia-Pacific Islanders. 
The treatment of early gastric cancer includes endoscopic resection and radical surgery. For endoscopic resection treatment, the American Gastroenterology Association (AGA) updated the clinical practice of endoscopic submucosal dissection in 2019, indicating that absolute indications for EGC endoscopic treatment include moderate and well-differentiated, ulcer-free mucosal lesions with a size $<2 \mathrm{~cm}$; the expanded indications were moderate and well-differentiated superficial cancers, $>2 \mathrm{~cm}$, lesions $<3 \mathrm{~cm}$ that are ulcerative or containing early submucosal infiltration, and poorly differentiated $<2 \mathrm{~cm}$ superficial cancers[26]. From our results, it can be seen that when the tumor is a poorly differentiated or undifferentiated submucosal tumor with a size $>2 \mathrm{~cm}$, the rate of lymph node metastasis will increase 2-4 times. Therefore, the expanded indications of endoscopic treatment in western countries should be employed with caution. In this study, we developed and validated a predictive model for evaluating LNM in EGC patients.With the help of the prediction model, we can accurately determine the high-risk patients with EGC at LNM and choose the best surgical treatment.

This study analyzed the survival prognosis of 2294 patients. The results showed that EGC patients with lymph node metastasis had the worst prognosis, which may be related to the likelihood of tumor recurrence caused by lymph node metastasis. At the same time, advanced age, male size, large tumor size and stage $T 1 \mathrm{~b}$ result in the poor prognosis of EGC patients. It is worth noting that race also affects the survival prognosis of EGC patients. Our results show that American Indians and Asian Pacific Islanders have a better prognosis than black and white patients, with black patients having the worst prognosis. The etiology of the difference in lymph node metastasis and survival outcome of EGC among different races is still unclear. The inherent molecular and biological differences between different ethnic groups may be the causes of the differences in survival among heterogeneous Western populations.

Studies in Asian countries have shown that the 5-year survival rate of EGC patients after effective treatment can reach more than $90 \%$ [27-29]. In this study, the Kaplan-Meier method was used to analyze the survival rate of EGC patients. The results showed that the 5-year tumor-specific survival rate of EGC patients without lymph node metastasis was $88.7 \%$, and the 5 -year tumor-specific survival rate of EGC patients with T1a was $91.4 \%$. This is similar to the 5-year survival rate of the Asian population. In other words, EGC patients without lymph node metastasis and T1a western populations can benefit from endoscopic treatment.We have also developed and validated a prognostic model for cancer-specific survival of patients with EGC. For patients with a high risk of poor prognosis, surgical resection and lymph node dissection alone are not enough, and further adjuvant treatment may be needed.

This study has some limitations and advantages. The SEER database was used in this study, which does not capture tumor ulcers, lymphatic infiltration, and other indicators that have been shown to be risk factors for lymph node metastasis in EGC patients in Asian countries and should be taken into account when deciding treatment for EGC patients[30,31]. Moreover, the SEER database covers only $28 \%$ of the U.S. population, with the possibility of sampling error. However, the SEER database is one of the largest registries allowing comparative analysis of EGC, providing a large sample size to assess risk factors for lymph node metastasis and survival outcomes in EGC patients by analyzing commonly used but often 
overlooked clinicopathological features.Finally, patients receiving adjuvant chemoradiotherapy were not included in this study, so an analysis of this specific population may be required.

In summary, tumor size, tumor grade and tumor infiltration depth are risk factors for lymph node metastasis of EGC.Endoscopic therapy for differentiated intramucosal tumors is an alternative therapy.For patients with prognostic risk factors, surgical treatment and lymph node dissection alone are not enough, and adjuvant therapy may be needed to improve survival rate.In this study, we established a reliable prediction model for lymph node metastasis of early gastric cancer and a prognostic model for early gastric cancer, providing a good basis for clinical treatment decision making.

\section{Declarations}

\section{Availability of data and materials}

The data that support the findings of this study are available from surveillance, epidemiology and end results [SEER] database but restrictions apply to the availability of these data, which were used under license for the current study, and so are not publicly available. Data are however available from the authors upon reasonable request and with permission of SEER.

\section{Authors' contributions}

H.K.T., Z.Zong. and Z.T..L. conceived and designed this study. Z.Zhang. and C.G.H. collected and assembled the data. H.K.T., Z.Zong. analysed and interpreted the data. H.K.T, Z.Zhang.and Z.T.L drafted the manuscript. C.G.H., J.L. prepared the figures and tables. All authors read and approved the final manuscript.

\section{Conflicts of interests}

The authors declare that there is no conflict of interest in this study.

\section{Funding}

This report was supported by the National Natural Science Foundation of China (Grant Number: 81860433), the Natural Science Youth Foundation of Jiangxi Province(Grant Number: 20192BAB215036) and Jiangxi Province Natural Science Key R\&D Project-General Project(Grant Number: 20202BBG73024).

\section{Acknowledgements}

The authors appreciate the efforts of the staff of the Surveillance, Epidemiology, and End Results (SEER) program and thank them for the availability of public access to the SEER database.

\section{References}


1. Bray, F., et al., Global cancer statistics 2018: GLOBOCAN estimates of incidence and mortality worldwide for 36 cancers in 185 countries. CA Cancer J Clin, 2018. 68(6): p. 394-424.

2. Balakrishnan, M., et al., Changing Trends in Stomach Cancer Throughout the World. Curr Gastroenterol Rep, 2017. 19(8): p. 36.

3. Ono, H., et al., Guidelines for endoscopic submucosal dissection and endoscopic mucosal resection for early gastric cancer. Dig Endosc, 2016. 28(1): p. 3-15.

4. Kuo, C.Y., Y. Chao and C.P. Li, Update on treatment of gastric cancer. J Chin Med Assoc, 2014. 77(7): p. 345-53.

5. Balmadrid, B. and J.H. Hwang, Endoscopic resection of gastric and esophageal cancer. Gastroenterol Rep (Oxf), 2015. 3(4): p. 330-8.

6. Gu, L., et al., Comparison of Long-Term Outcomes of Endoscopic Submucosal Dissection and Surgery for Early Gastric Cancer: a Systematic Review and Meta-analysis. J Gastrointest Surg, 2019. 23(7): p. 1493-1501.

7. Wang, X., et al., Multidisciplinary Approach in Improving Survival Outcome of Early-Stage Gastric Cancer. J Surg Res, 2020. 255: p. 285-296.

8. Najmeh, S., et al., Comparing Laparoscopic to Endoscopic Resections for Early Gastric Cancer in a High Volume North American Center. J Gastrointest Surg, 2016. 20(9): p. 1547-53.

9. Kondo, A., et al., Endoscopy vs surgery in the treatment of early gastric cancer: Systematic review. World J Gastroenterol, 2015. 21(46): p. 13177-87.

10. Oh, S.Y., et al., Outcomes of minimally invasive surgery for early gastric cancer are comparable with those for open surgery: analysis of 1,013 minimally invasive surgeries at a single institution. Surg Endosc, 2014. 28(3): p. 789-95.

11. Dumoulin, F.L., et al., Endoscopic Submucosal Dissection (ESD) in Colorectal Tumors. Viszeralmedizin, 2014. 30(1): p. 39-44.

12. Zhao, B.W., et al., Lymph Node Metastasis, a Unique Independent Prognostic Factor in Early Gastric Cancer. PLoS One, 2015. 10(7): p. e0129531.

13. Kinami, S., et al., Precision surgical approach with lymph-node dissection in early gastric cancer. World J Gastroenterol, 2019. 25(14): p. 1640-1652.

14. Ahmad, R., et al., Predictors of Lymph Node Metastasis in Western Early Gastric Cancer. J Gastrointest Surg, 2016. 20(3): p. 531-8.

15. Japanese gastric cancer treatment guidelines 2014 (ver. 4). Gastric Cancer, 2017. 20(1): p. 1-19.

16. Edge, S.B. and C.C. Compton, The American Joint Committee on Cancer: the 7th edition of the AJCC cancer staging manual and the future of TNM. Ann Surg Oncol, 2010. 17(6): p. 1471-4.

17. El-Sedfy, A., S.S. Brar and N.G. Coburn, Current role of minimally invasive approaches in the treatment of early gastric cancer. World J Gastroenterol, 2014. 20(14): p. 3880-8.

18. Bhatt, A., et al., Indications and Techniques for Endoscopic Submucosal Dissection. Am J Gastroenterol, 2015. 110(6): p. 784-91. 
19. Bausys, R., et al., Propensity score-matched comparison of short-term and long-term outcomes between endoscopic submucosal dissection and surgery for treatment of early gastric cancer in a Western setting. Surg Endosc, 2019. 33(10): p. 3228-3237.

20. Bourke, M.J., H. Neuhaus and J.J. Bergman, Endoscopic Submucosal Dissection: Indications and Application in Western Endoscopy Practice. Gastroenterology, 2018. 154(7): p. 1887-1900.e5.

21. Saito, T., et al., Accuracy of multidetector-row CT in diagnosing lymph node metastasis in patients with gastric cancer. Eur Radiol, 2015. 25(2): p. 368-74.

22. Mocellin, S. and S. Pasquali, Diagnostic accuracy of endoscopic ultrasonography (EUS) for the preoperative locoregional staging of primary gastric cancer. Cochrane Database Syst Rev, 2015(2): p. CD009944.

23. Yang, B., et al., Large population-based study using the SEER database: is endoscopic resection appropriate for early gastric cancer patients in the United States? Scand J Gastroenterol, 2020. 55(7): p. 834-842.

24. Chu, Y.N., et al., Feasibility of endoscopic treatment and predictors of lymph node metastasis in early gastric cancer. World J Gastroenterol, 2019. 25(35): p. 5344-5355.

25. Kamiya, S., et al., Auxiliary diagnosis of lymph node metastasis in early gastric cancer using quantitative evaluation of sentinel node radioactivity. Gastric Cancer, 2016. 19(4): p. 1080-1087.

26. Draganov, P.V., et al., AGA Institute Clinical Practice Update: Endoscopic Submucosal Dissection in the United States. Clin Gastroenterol Hepatol, 2019. 17(1): p. 16-25.e1.

27. Saragoni, L., et al., Early gastric cancer: diagnosis, staging, and clinical impact. Evaluation of 530 patients. New elements for an updated definition and classification. Gastric Cancer, 2013. 16(4): p. 549-54.

28. Tong, J.H., et al., Early gastric cancer with signet-ring cell histologic type: risk factors of lymph node metastasis and indications of endoscopic surgery. Surgery, 2011. 149(3): p. 356-63.

29. Sun, K., et al., Endoscopic resection versus surgery for early gastric cancer: a systematic review and meta-analysis. Dig Endosc, 2016. 28(5): p. 513-25.

30. Li, X., et al., The Characteristics, Prognosis, and Risk Factors of Lymph Node Metastasis in Early Gastric Cancer. Gastroenterol Res Pract, 2018. 2018: p. 6945743.

31. Kim, S.M., et al., Nomogram to predict lymph node metastasis in patients with early gastric cancer: a useful clinical tool to reduce gastrectomy after endoscopic resection. Endoscopy, 2020. 52(6): p. 435443.

\section{Tables}

Table 1. Characteristics of study subjects and lymph node metastasis rate 


\begin{tabular}{|c|c|c|c|c|}
\hline \multirow[t]{2}{*}{ Variable } & \multirow[t]{2}{*}{$\begin{array}{l}\text { Total } \ n \% \\
2294 \rrbracket\end{array}$} & $\begin{array}{l}\text { lymph node metastasis } \\
\text { \n\%】 }\end{array}$ & $\begin{array}{l}\text { lymph node metastasis } \\
\text { Øn\%囚 }\end{array}$ & \multirow[t]{2}{*}{$\begin{array}{l}P \\
\text { value }\end{array}$} \\
\hline & & NO(1961) & YES(333) & \\
\hline Age(years) & & & & 0.063 \\
\hline$<50$ & 191(8.3\%) & 153(80.1\%) & $38(19.9 \%)$ & \\
\hline $50-60$ & $380(16.5 \%)$ & 321(84.4\%) & $59(15.6 \%)$ & \\
\hline $60-70$ & $661(28.8 \%)$ & $568(85.9 \%)$ & $93(14.1 \%)$ & \\
\hline $70-80$ & 678(29.5\%) & 577(85.1\%) & 101(14.9\%) & \\
\hline$>80$ & $384(16.9 \%)$ & $342(89.0 \%)$ & 42(11.0\%) & \\
\hline Race & & & & 0.004 \\
\hline White & 1441(62.8\%) & $1257(87.2 \%)$ & 184(12.8\%) & \\
\hline Black & $279(12.1 \%)$ & $224(80.2 \%)$ & $55(19.8 \%)$ & \\
\hline Others & $574(25.1 \%)$ & 480(83.6\%) & $94(16.4 \%)$ & \\
\hline Sex & & & & 0.843 \\
\hline Male & $1401(61.0 \%)$ & 1196(85.3\%) & $205(14.7 \%)$ & \\
\hline Female & $893(39.0 \%)$ & 765(85.6\%) & $128(14.4 \%)$ & \\
\hline Tumor size & & & & 0.000 \\
\hline$<2 \mathrm{~cm}$ & 1011(44.0\%) & 908(89.8\%) & 103(10.2\%) & \\
\hline $2-5 \mathrm{~cm}$ & 767(33.4\%) & 603(78.6\%) & $164(21.4 \%)$ & \\
\hline$>5 \mathrm{~cm}$ & $125(5.4 \%)$ & $78(62.4 \%)$ & $47(37.6 \%)$ & \\
\hline unknown & $391(17.2 \%)$ & $372(95.1 \%)$ & $19(4.9 \%)$ & \\
\hline Grade & & & & 0.000 \\
\hline Grade I & $351(15.3 \%)$ & $335(95.4 \%)$ & $16(4.6 \%)$ & \\
\hline Grade II & 755(32.9\%) & $656(86.8 \%)$ & $99(13.2 \%)$ & \\
\hline Grade III/IV & $916(39.9 \%)$ & 710(77.5\%) & $206(22.5 \%)$ & \\
\hline unknown & $272(11.9 \%)$ & $260(95.5 \%)$ & $12(4.5 \%)$ & \\
\hline Organization Type & & & & 0.012 \\
\hline Adenocarcinoma & 1793(78.1\%) & 1553(86.6\%) & $240(13.6 \%)$ & \\
\hline $\begin{array}{l}\text { Signet ring cell } \\
\text { carcinoma }\end{array}$ & $351(15.3 \%)$ & $288(82.0 \%)$ & $63(18.0 \%)$ & \\
\hline
\end{tabular}




\begin{tabular}{|lllll|}
\hline Depth & $150(6.6 \%)$ & $120(82.0 \%)$ & $30(18.0 \%)$ & 0.000 \\
T1a & & & & \\
T1b & $1145(56.3 \%)$ & $1083(94.5 \%)$ & $62(5.5 \%)$ & 0.017 \\
\hline Primary site & $1149(43.7 \%)$ & $878(76.4 \%)$ & $271(23.6 \%)$ & \\
Cardia & & & $79(11.2 \%)$ & \\
Fundus & $706(30.8 \%)$ & $627(88.8 \%)$ & $6(11.0 \%)$ & \\
Body & $55(2.4 \%)$ & $49(89.0 \%)$ & $42(16.8 \%)$ & \\
Antrum & $251(10.9 \%)$ & $209(83.2 \%)$ & $108(16.3 \%)$ & \\
Pylorus & $666(29.1 \%)$ & $558(83.7 \%)$ & $31(14.4 \%)$ \\
Lesser curve & $64(2.7 \%)$ & $47(73.4 \%)$ & $14(15.7 \%)$ \\
Greater curve & $216(9.4 \%)$ & $185(85.6 \%)$ & $36(14.6 \%)$ \\
Overlapping/NOS & $24(3.9 \%)$ & $75(84.3 \%)$ & $211(85.4 \%)$ & \\
\hline
\end{tabular}

Table 2. Multivariate analysis of the risk of LNM in EGC 


\begin{tabular}{|c|c|c|c|}
\hline Variable & Total『n\% 2294】 & $\mathrm{OR}(95 \% \mathrm{Cl})$ & $\begin{array}{l}\mathrm{P} \\
\text { value }\end{array}$ \\
\hline Age(years) & & & 0.057 \\
\hline$<50$ & 191(8.3\%) & $2.191(1.280-3.751)$ & 0.004 \\
\hline $50-60$ & $380(16.5 \%)$ & $1.703(1.070-2.710)$ & 0.025 \\
\hline $60-70$ & $661(28.8 \%)$ & $1.478(0.971-2.251)$ & 0.068 \\
\hline $70-80$ & $678(29.5 \%)$ & $1.412(0.936-2.129)$ & 0.100 \\
\hline$>80$ & $384(16.9 \%)$ & 1(Reference) & \\
\hline Race & & & 0.085 \\
\hline White & $1441(62.8 \%)$ & 1(Reference) & \\
\hline Black & $279(12.1 \%)$ & $1.518(1.039-2.218)$ & 0.031 \\
\hline Others & $574(25.1 \%)$ & $1.202(0.885-1.632)$ & 0.239 \\
\hline Tumor size & & & 0.000 \\
\hline$<2 \mathrm{~cm}$ & $1011(44.0 \%)$ & 1(Reference) & \\
\hline $2-5 \mathrm{~cm}$ & 767(33.4\%) & $1.766(1.330-2.343)$ & 0.000 \\
\hline$>5 \mathrm{~cm}$ & $125(5.4 \%)$ & $4.308(2.738-6.779)$ & 0.000 \\
\hline unkown & $391(17.2 \%)$ & $0.750(0.437-1.288)$ & 0.297 \\
\hline Grade & & & 0.000 \\
\hline Grade I & $351(15.3 \%)$ & 1(Reference) & \\
\hline Grade II & 755(32.9\%) & $2.273(1.295-3.991)$ & 0.004 \\
\hline Grade III/IV & $916(39.9 \%)$ & $3.957(2.263-6.919)$ & 0.000 \\
\hline unknown & $272(11.9 \%)$ & $1.647(0.734-3.695)$ & 0.226 \\
\hline Depth & & & 0.000 \\
\hline T1a & $1145(56.3 \%)$ & 1(Reference) & \\
\hline T1b & $1149(43.7 \%)$ & $4.108(2.994-5.637)$ & 0.000 \\
\hline Organization Type & & & 0.938 \\
\hline Adenocarcinoma & 1793(78.1\%) & 1(Reference) & \\
\hline \multirow{2}{*}{$\begin{array}{l}\text { Signet ring cell carcinoma } \\
\text { others }\end{array}$} & $351(15.3 \%)$ & $1.068(0.734-1.553)$ & 0.731 \\
\hline & $150(6.6 \%)$ & $1.047(0.643-1.703)$ & 0.853 \\
\hline
\end{tabular}




\begin{tabular}{|c|c|c|c|}
\hline Primary site & & & 0.383 \\
\hline Cardia & $706(30.8 \%)$ & 1(Reference) & \\
\hline Fundus & $55(2.4 \%)$ & $0.776(0.306-1.970)$ & 0.5940 .781 \\
\hline Body & $251(10.9 \%)$ & $1.067(0.678-1.678)$ & 0.707 \\
\hline Antrum & $666(29.1 \%)$ & $1.072(0.746-1.540)$ & 0.034 \\
\hline Pylorus & $64(2.7 \%)$ & $2.159(1.059-4.402)$ & 0.412 \\
\hline Lesser curve & $216(9.4 \%)$ & $0.810(0.490-1.340)$ & 0.596 \\
\hline Greater curve & $89(3.9 \%)$ & $0.832(0.420-1.646)$ & 0.869 \\
\hline Overlapping/NOS & $247(10.8 \%)$ & $0.961(0.601-1.537)$ & \\
\hline
\end{tabular}

Table 3. Analysis of influencing factors of overall survival rate and tumor-specific survival rate of early gastric cancer 


\begin{tabular}{|c|c|c|c|c|}
\hline \multirow[t]{2}{*}{ Variable } & OS & $\mathrm{P}$ & CSS & $\mathrm{P}$ \\
\hline & $\mathrm{OR}(95 \% \mathrm{Cl})$ & value & $\mathrm{OR}(95 \% \mathrm{Cl})$ & value \\
\hline Age(years) & & 0.000 & & 0.000 \\
\hline$<50$ & 1(Reference) & & 1(Reference) & \\
\hline $50-60$ & $1.344(0.757-2.385)$ & 0.313 & $1.489(0.724-3.063)$ & 0.280 \\
\hline $60-70$ & $2.256(1.336-3.811)$ & 0.002 & $2.318(1.193-4.506)$ & 0.013 \\
\hline $70-80$ & $2.792(1.660-4.696)$ & 0.000 & $2.266(1.164-4.411)$ & 0.016 \\
\hline$>80$ & $6.330(3.756-10.667)$ & 0.000 & $4.388(2.231-8.629)$ & 0.000 \\
\hline Race & & 0.000 & & 0.000 \\
\hline White & 1(Reference) & & 1(Reference) & \\
\hline Black & $1.305(1.043-1.748)$ & 0.023 & $1.241(0.872-1.767)$ & 0.230 \\
\hline Others & $0.586(0.459-0.749)$ & 0.000 & $0.513(0.361-0.727)$ & 0.000 \\
\hline \multicolumn{5}{|l|}{ Sex } \\
\hline Male & 1(Reference) & & 1(Reference) & \\
\hline Female & $0.633(0.519-0.772)$ & 0.000 & $0.653(0.496-0.860)$ & 0.002 \\
\hline Tumor size & & 0.001 & & 0.002 \\
\hline$<2 \mathrm{~cm}$ & 1(Reference) & & 1(Reference) & \\
\hline $2-5 \mathrm{~cm}$ & $1.345(1.082-1.673)$ & 0.008 & $1.580(1.167-2.140)$ & 0.003 \\
\hline$>5 \mathrm{~cm}$ & $1.976(1.405-2.780)$ & 0.000 & $2.216(1.408-3.488)$ & 0.000 \\
\hline Grade & & 0.576 & & 0.106 \\
\hline Grade I & 1(Reference) & & 1(Reference) & \\
\hline Grade II & $0.874(0.654-1.168)$ & 0.363 & $0.840(0.548-1.287)$ & 0.423 \\
\hline Grade III/IV & $1.005(0.754-1.338)$ & 0.975 & $1.157(0.767-1.746)$ & 0.486 \\
\hline \multicolumn{5}{|l|}{ Depth } \\
\hline T1a & 1(Reference) & & 1(Reference) & \\
\hline
\end{tabular}




\section{lymph node metastasis}

$\begin{array}{lllll}\text { N0 } & 1 \text { (Reference) } & & 1 \text { (Reference) } & \\ \text { N1-3 } & 1.538(1.214-1.949) & 0.000 & 2.000(1.489-2.685) & 0.000\end{array}$

\section{Figures}

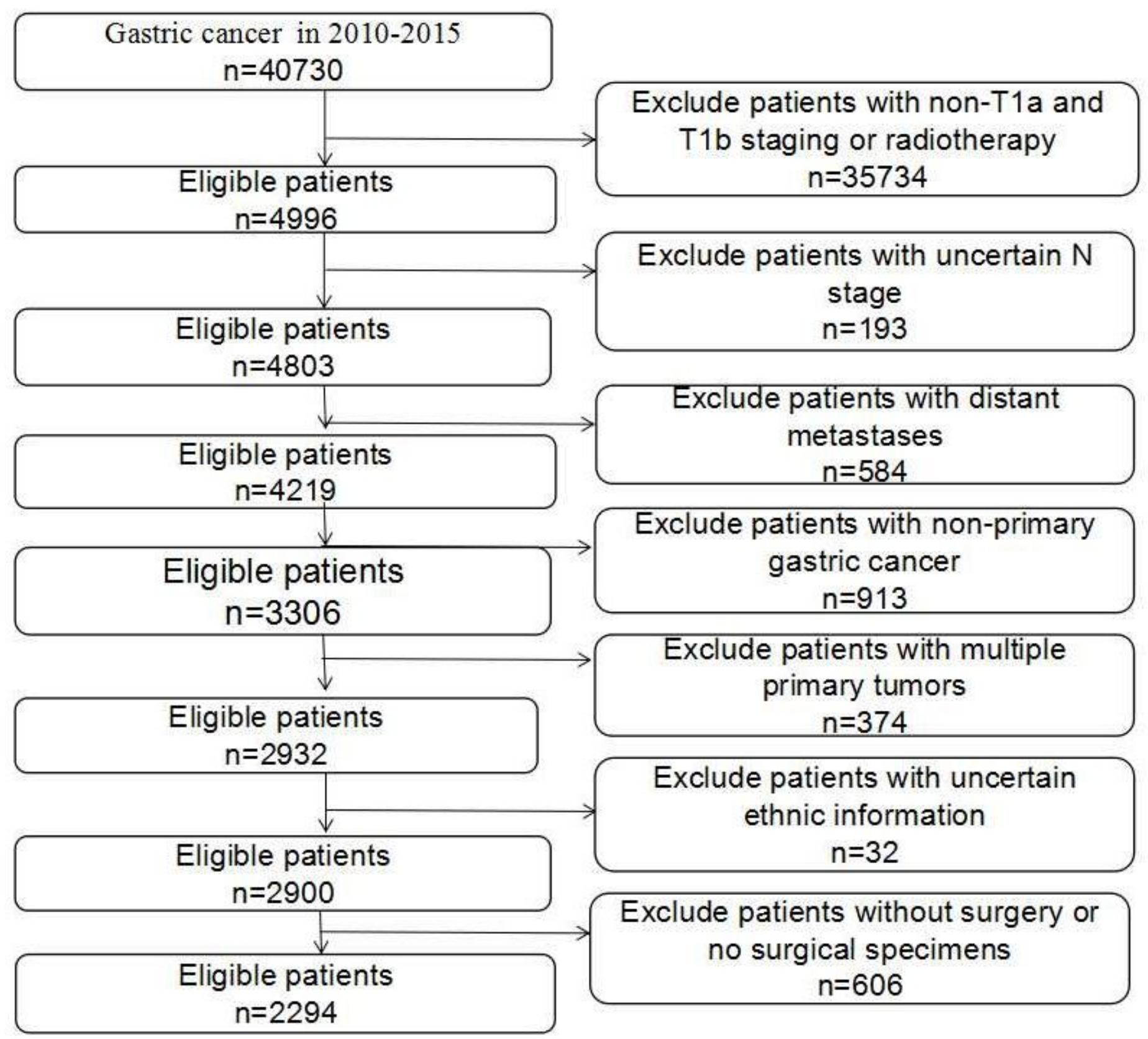

Figure 1

Patients were obtained with selection flow sheet 


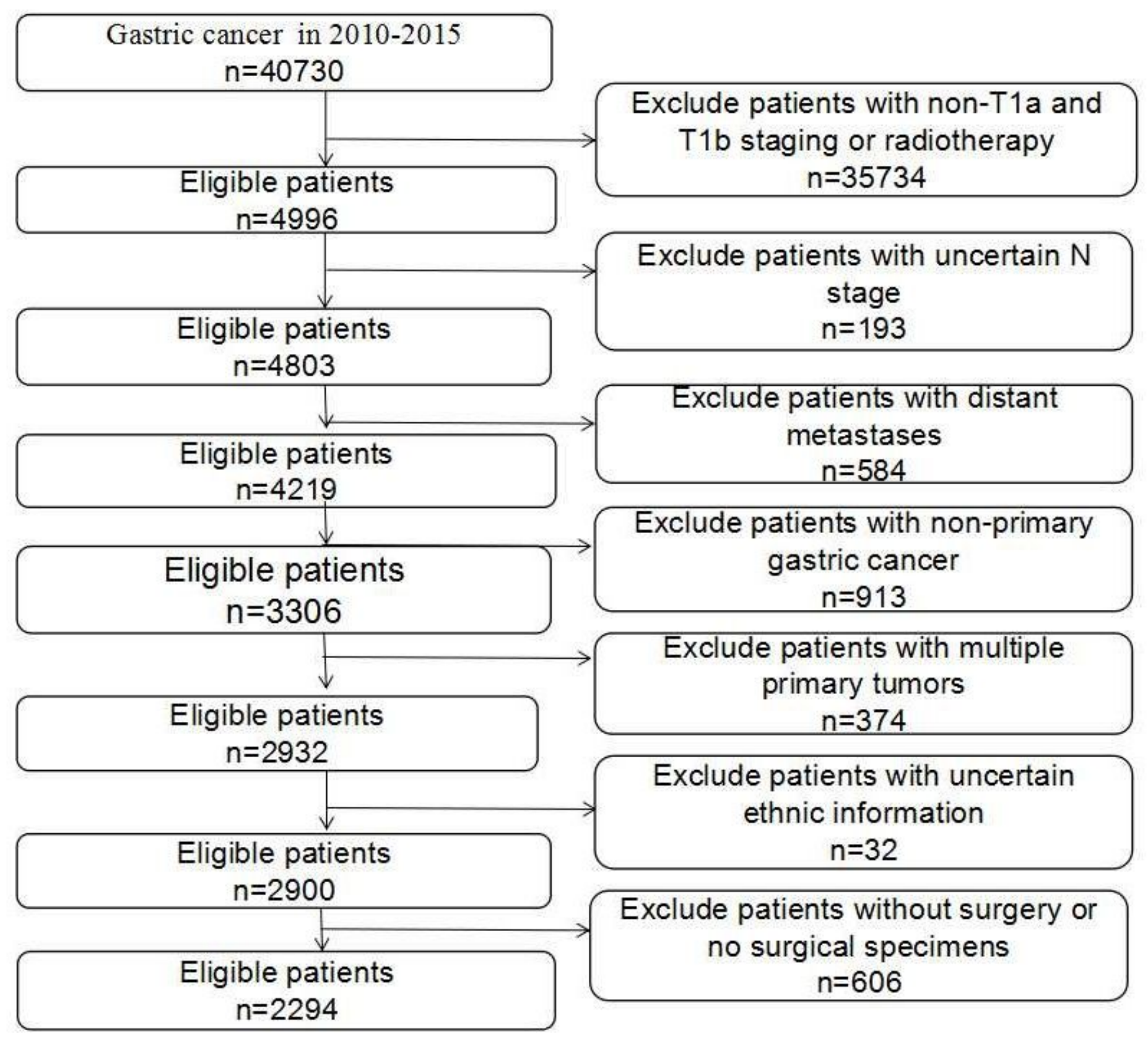

Figure 1

Patients were obtained with selection flow sheet 


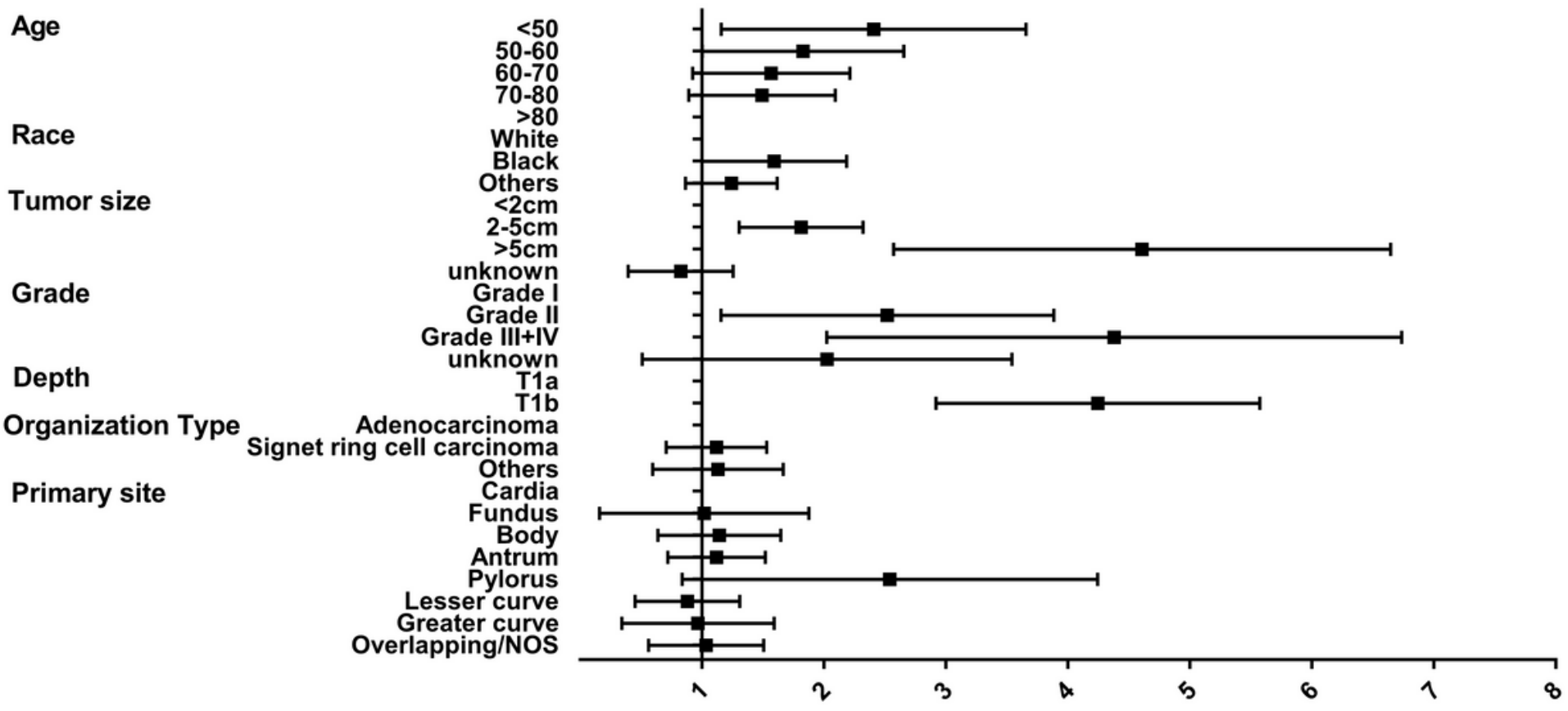

Figure 2

Multi-factor analysis forest diagram of lymph node metastasis in early gastric cancer

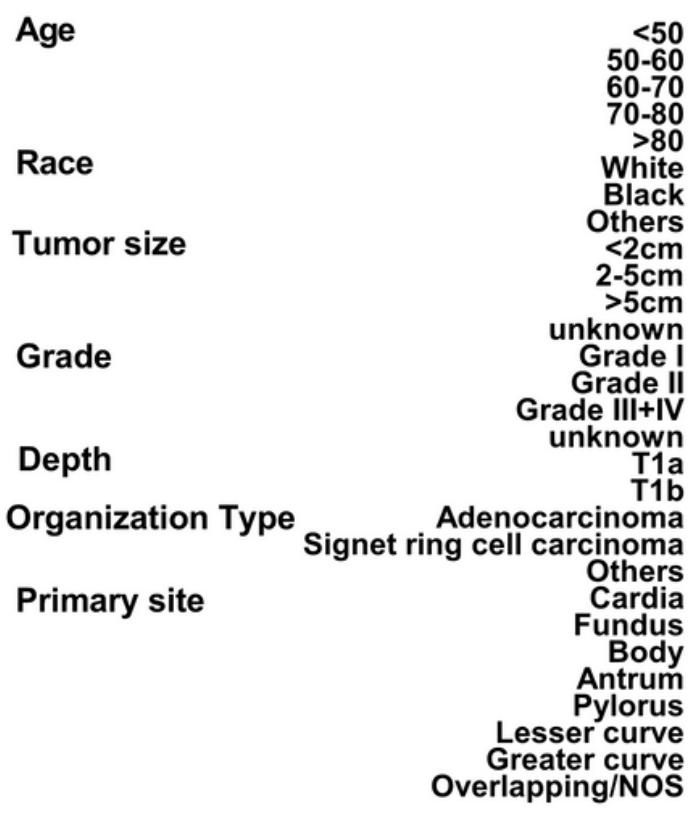

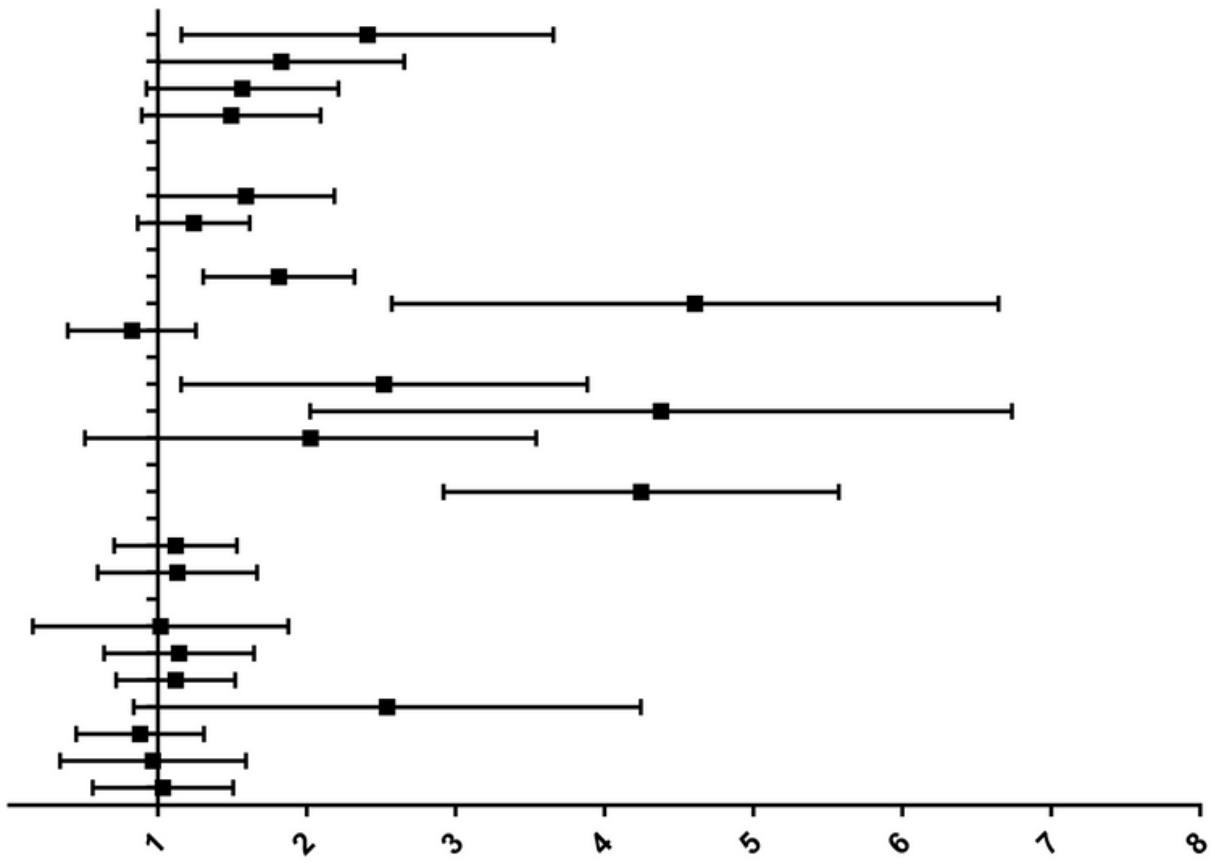

Figure 2

Multi-factor analysis forest diagram of lymph node metastasis in early gastric cancer 
$\begin{array}{lllllllllll}0 & 10 & 20 & 30 & 40 & 50 & 60 & 70 & 80 & 90 & 100\end{array}$

Tumor_size

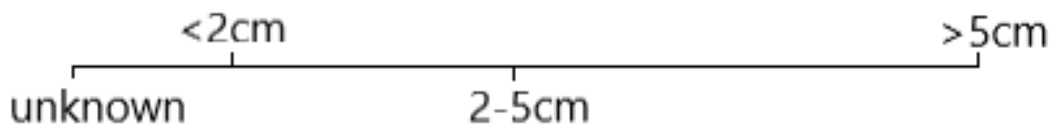

T_Stage

$\mathrm{T} 1 \mathrm{~b}$

T1a

Grate

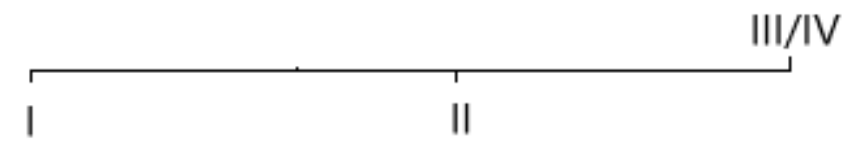

Total Points

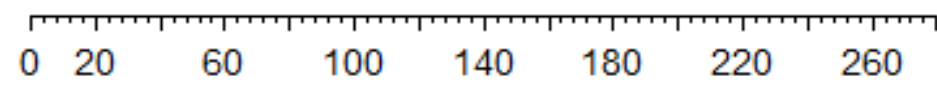

risk of lymph node metastasis

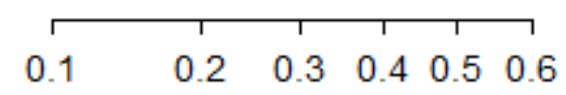

Figure 3

A nomogram for predicting lymph node metastasis in patients with EGC

Points

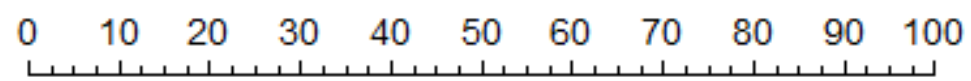

Tumor_size

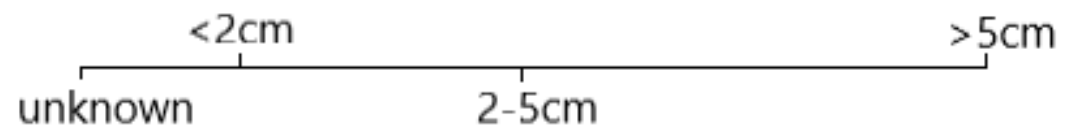

T_Stage

T1b

T1a

Grate

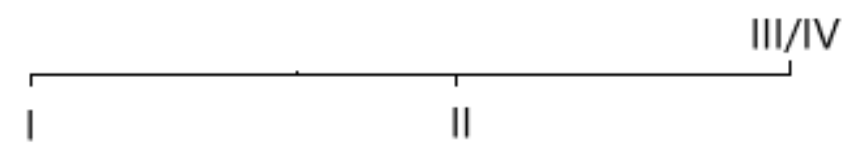

Total Points

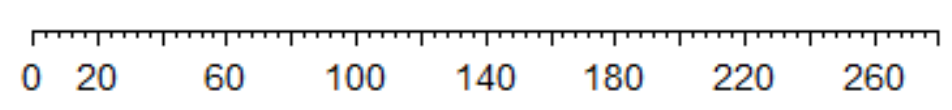

risk of lymph node metastasis

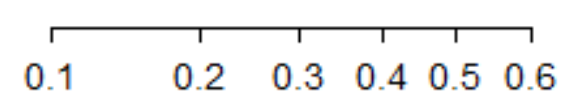


Figure 3

A nomogram for predicting lymph node metastasis in patients with EGC

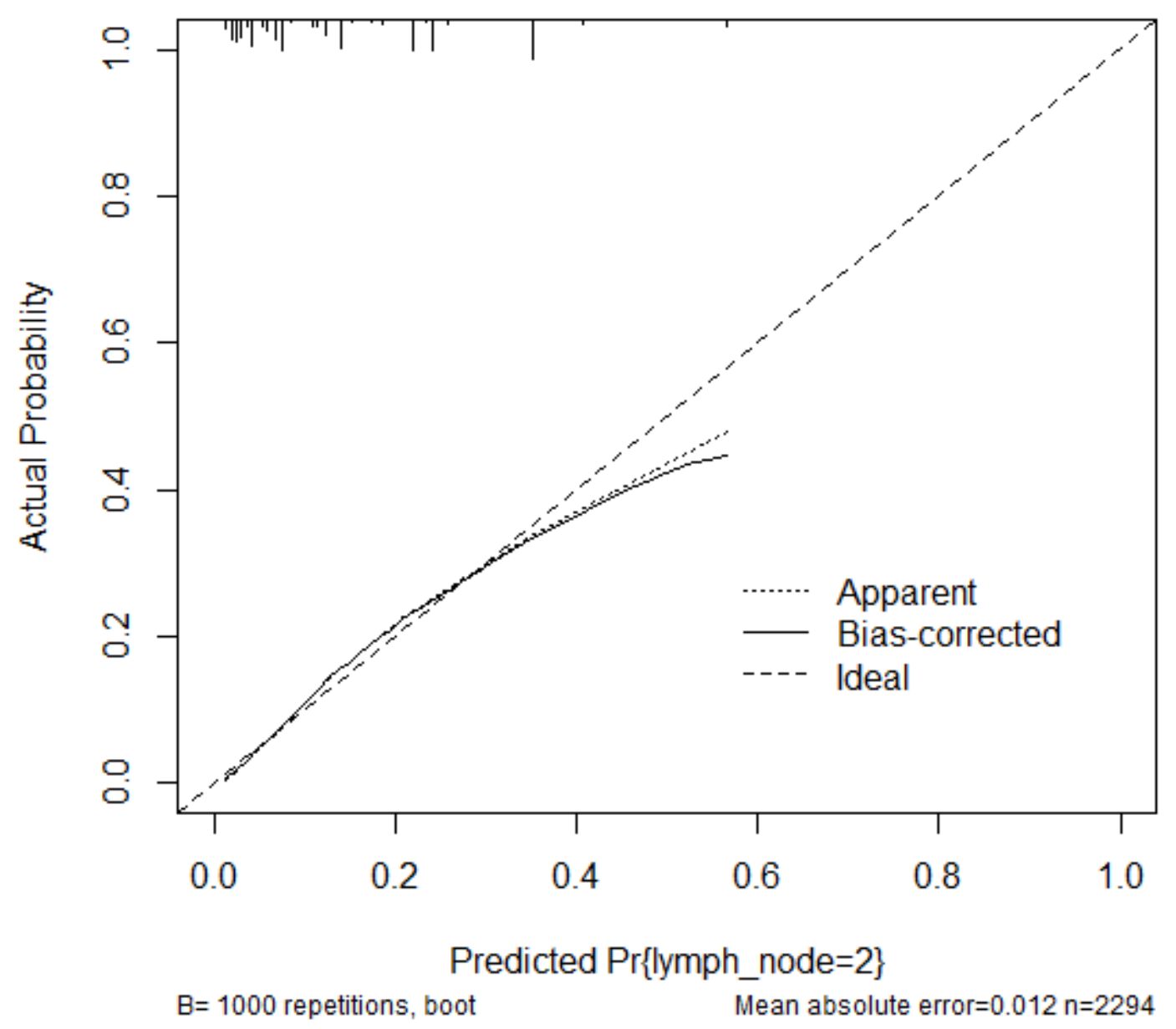

Figure 4

Correction graph of nomogram (internal verification set, after repeated 1000 times of bootstrap, $\mathrm{C}$ index is 0.771) 


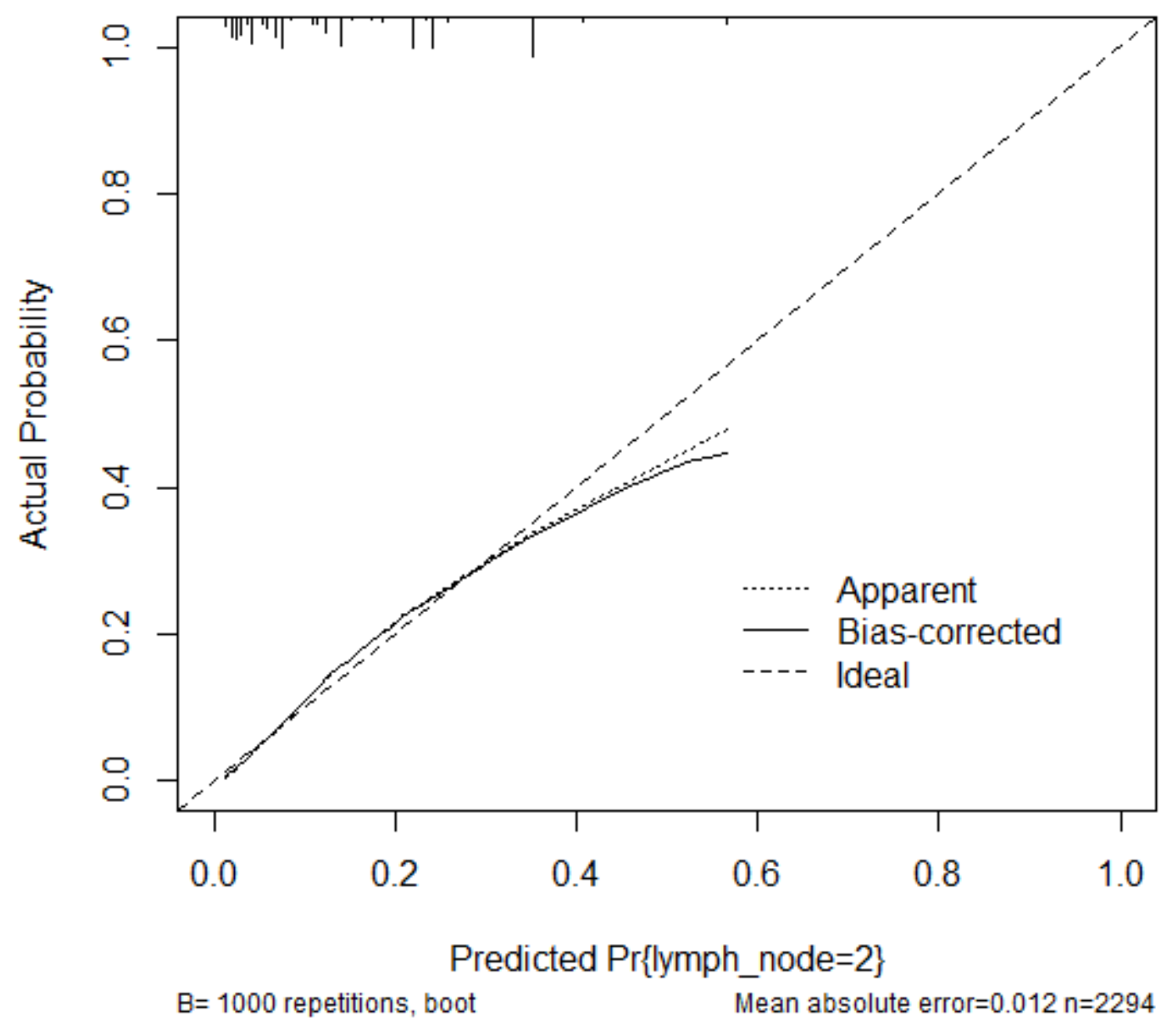

Figure 4

Correction graph of nomogram (internal verification set, after repeated 1000 times of bootstrap, $\mathrm{C}$ index is 0.771) 


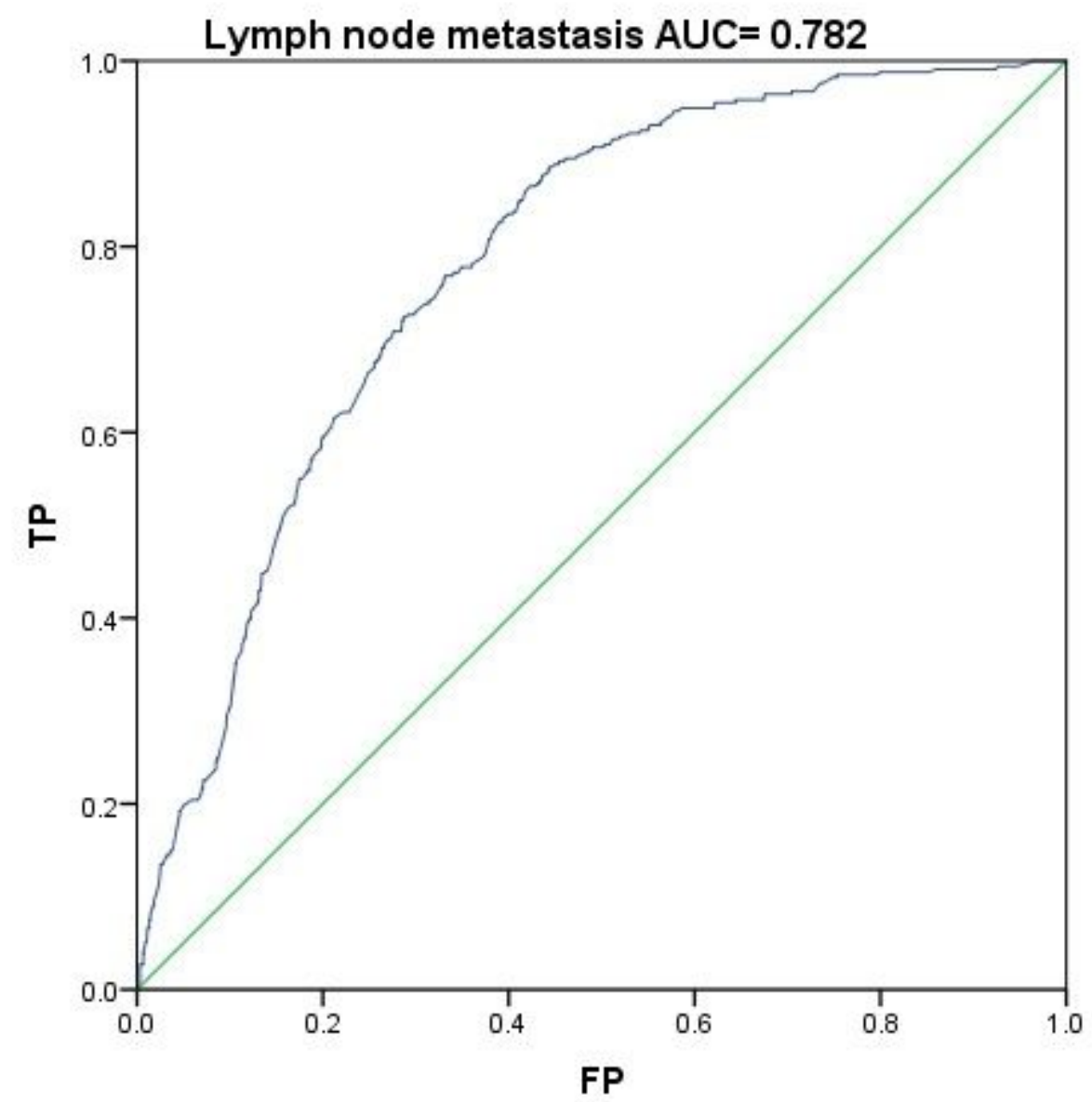

Figure 5

ROC curve for predicting risk factors of lymph node metastasis in EGC $(A U C=0.782)$ 


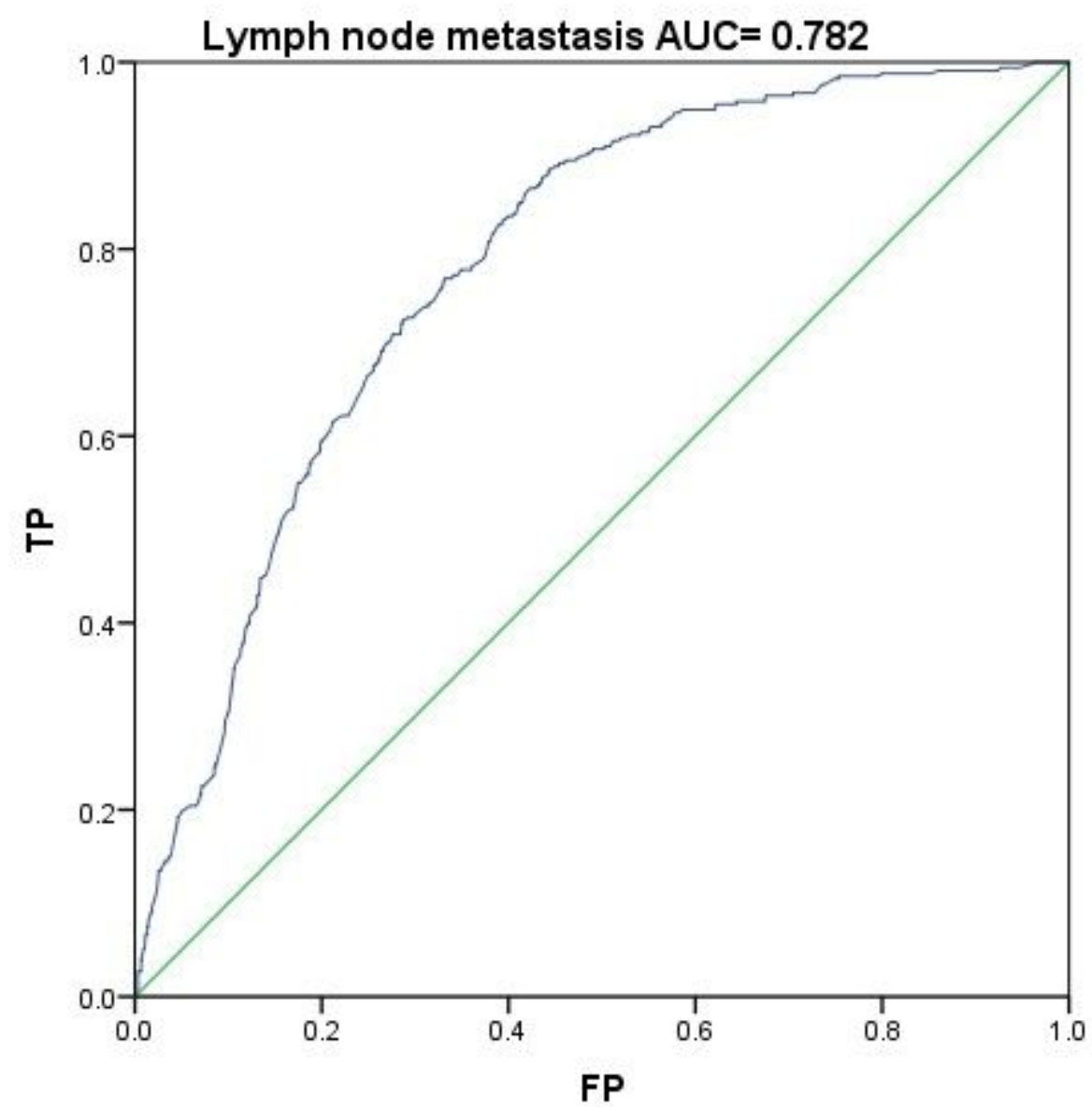

Figure 5

ROC curve for predicting risk factors of lymph node metastasis in EGC $(A U C=0.782)$

A

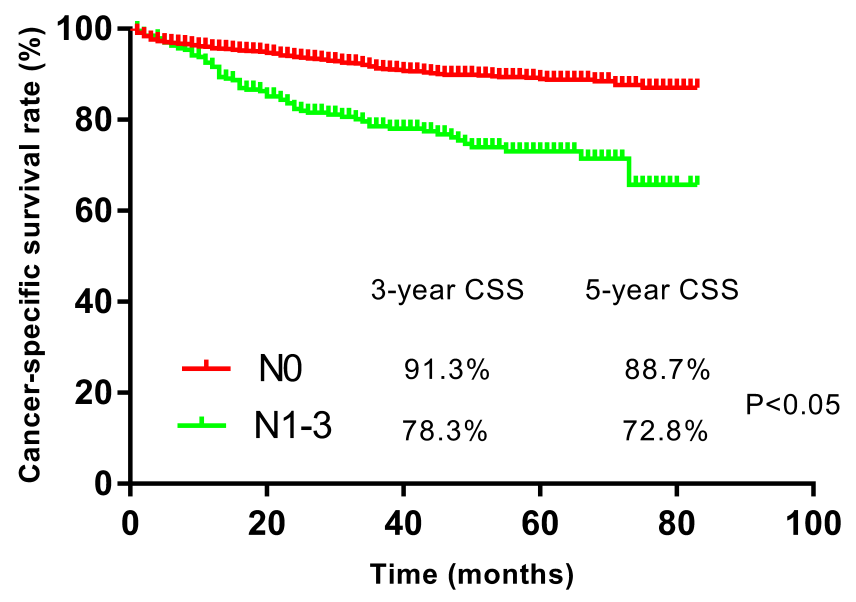

B

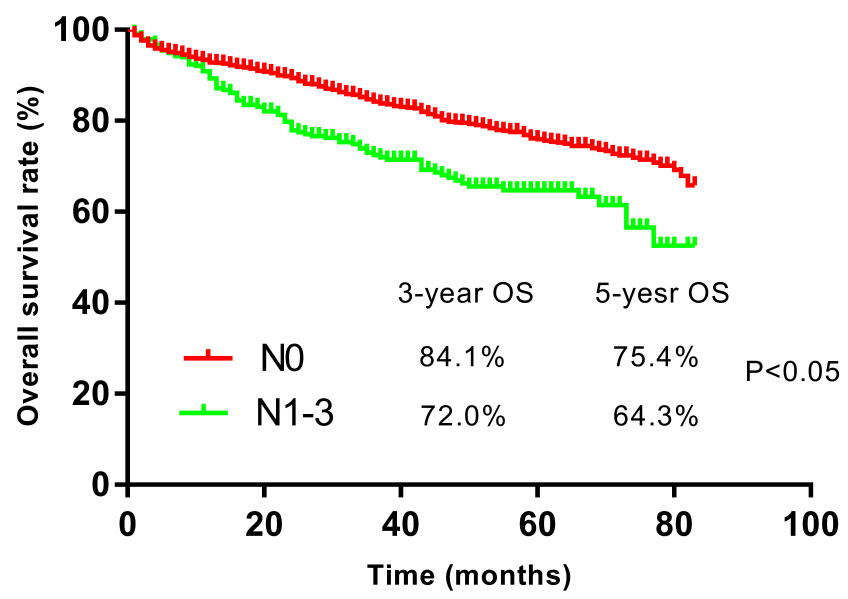

Figure 6

Tumor-specific survival rate $(A)$ and overall survival rate $(B)$ for lymph node metastasis 
A

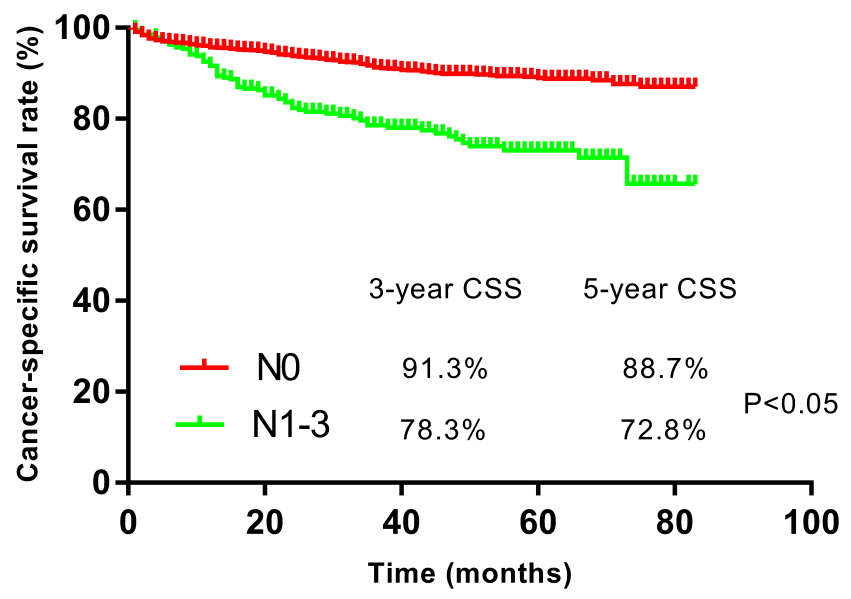

B

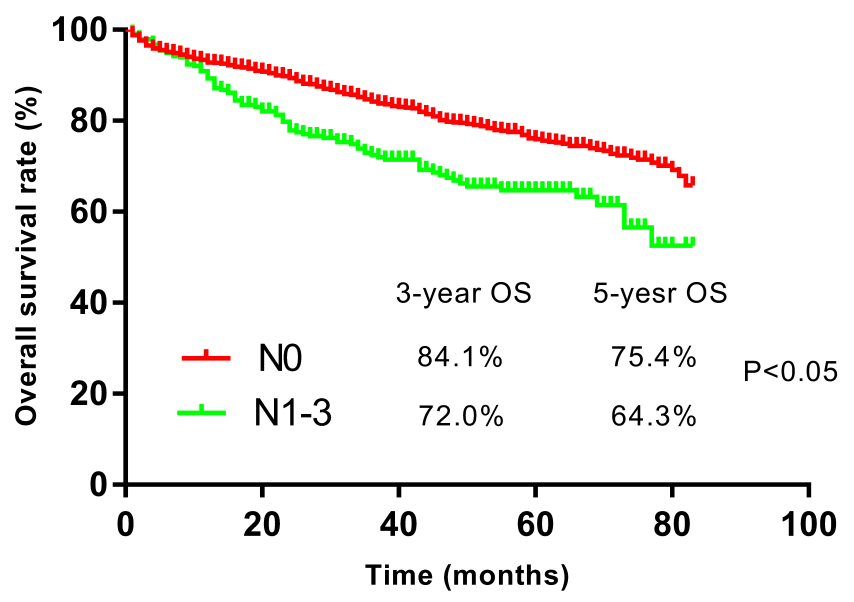

Figure 6

Tumor-specific survival rate (A) and overall survival rate (B) for lymph node metastasis

A

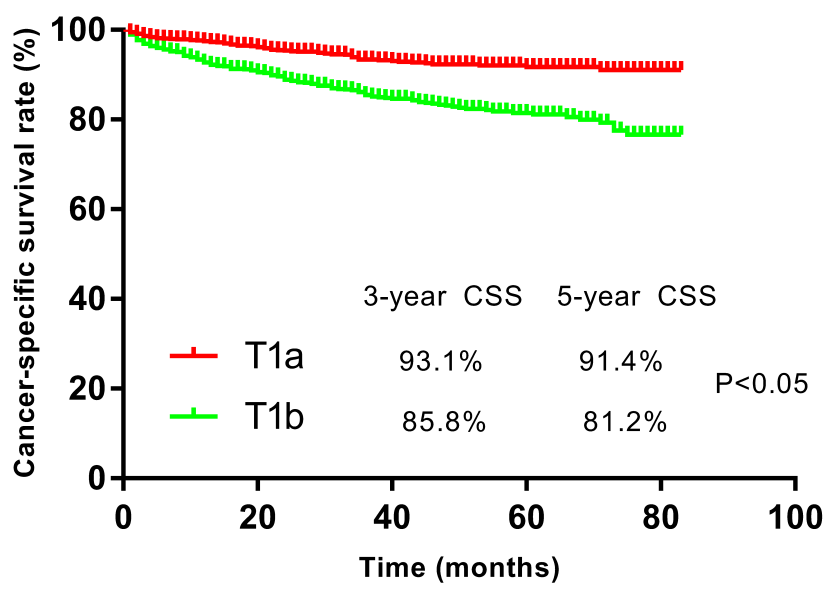

B

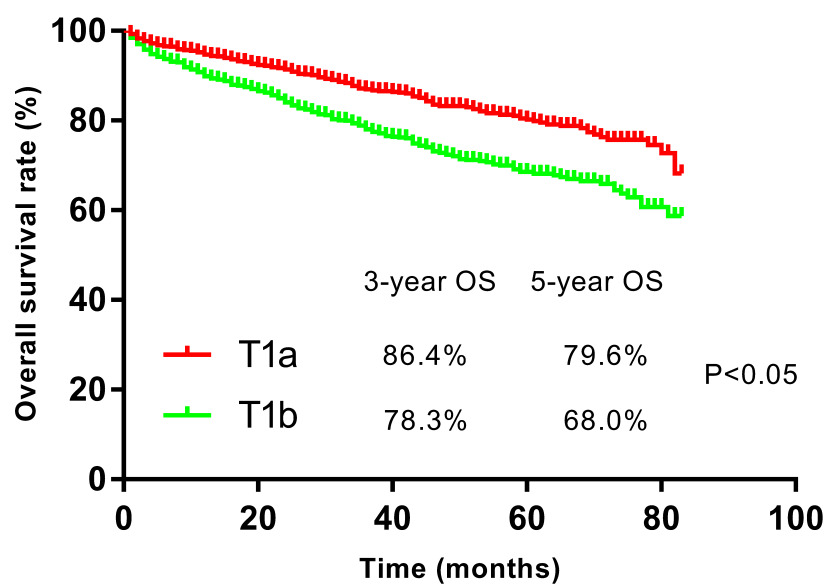

Figure 7

Tumor-specific survival rate (A) and overall survival rate (B) at the depth of tumor invasion 
A

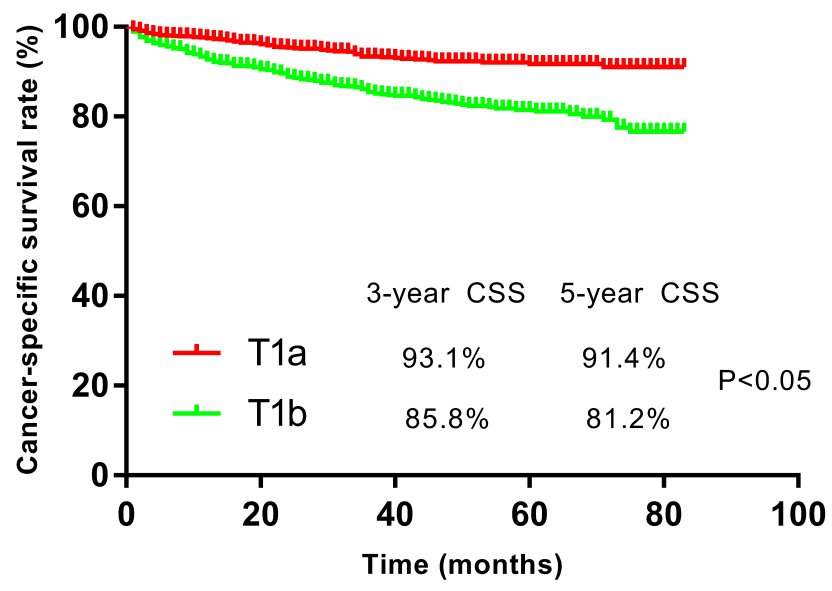

B

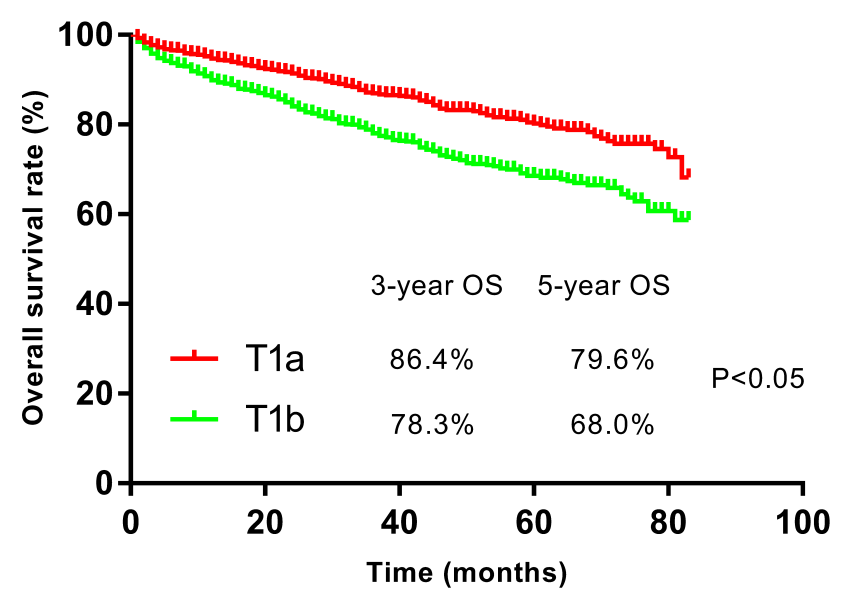

Figure 7

Tumor-specific survival rate (A) and overall survival rate (B) at the depth of tumor invasion 
Points

$\begin{array}{lllllllllll}0 & 10 & 20 & 30 & 40 & 50 & 60 & 70 & 80 & 90 & 100\end{array}$

Age

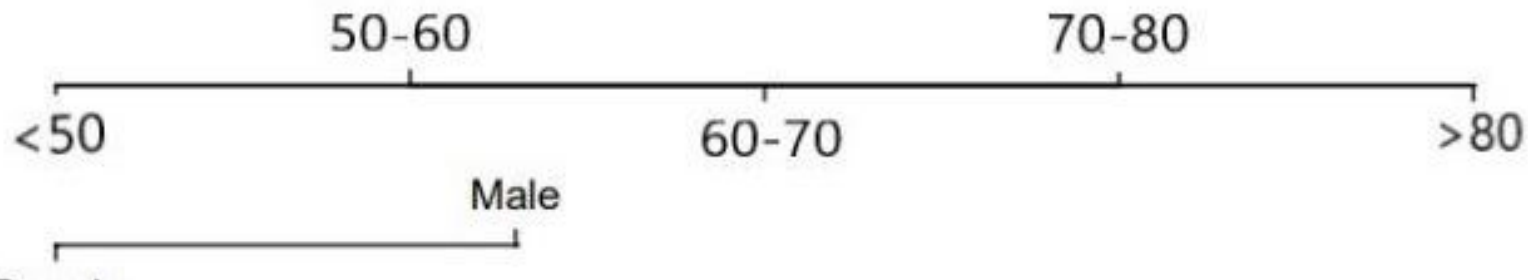

Sex

\section{Female}

Race

White

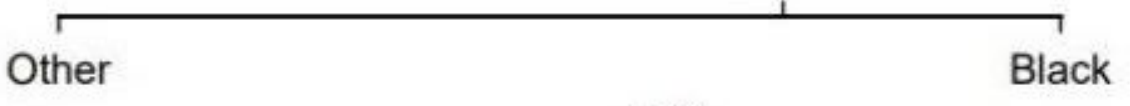

T_Stage

T1b

T1a

Tumor_size

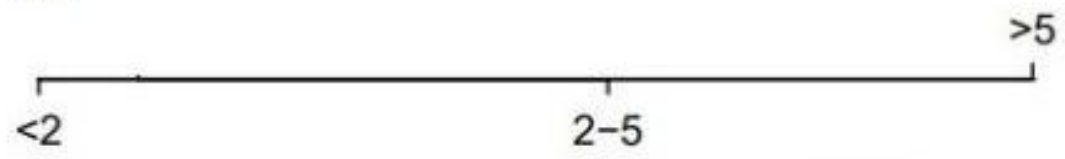

lymph_node

N1-3

No

Total Points

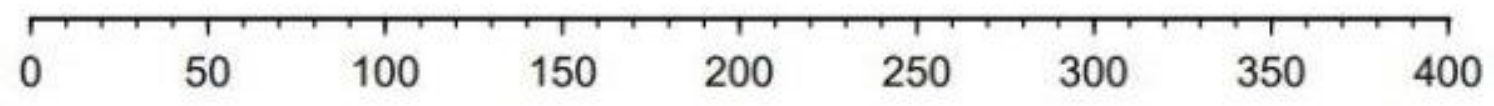

3-Year Survival

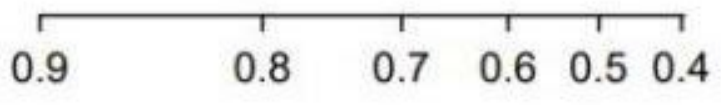

5-Year survival

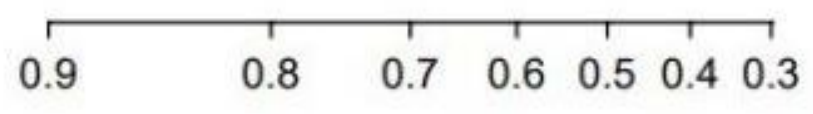

Figure 8

A nomogram for predicting the CSS survival rate of patients with EGC 
Points

$\begin{array}{lllllllllll}0 & 10 & 20 & 30 & 40 & 50 & 60 & 70 & 80 & 90 & 100\end{array}$

Age

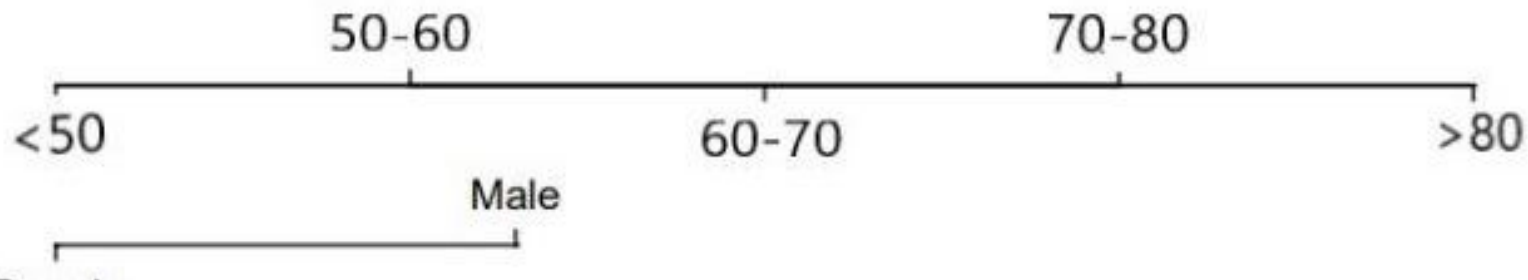

Sex

\section{Female}

Race

White

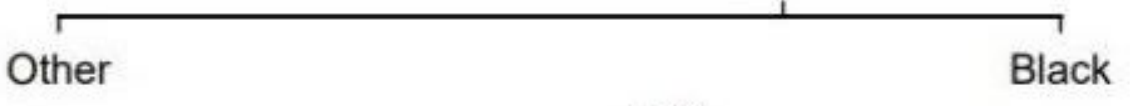

T_Stage

T1b

T1a

Tumor_size

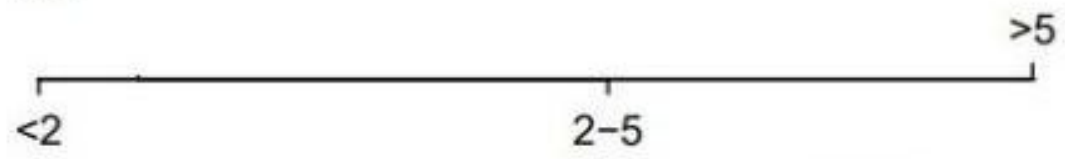

lymph_node

N1-3

No

Total Points

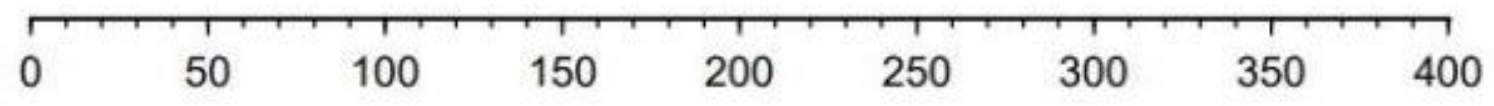

3-Year Survival

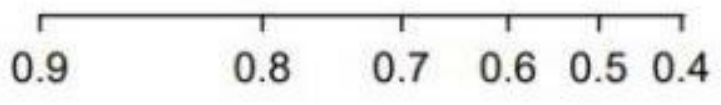

5-Year survival

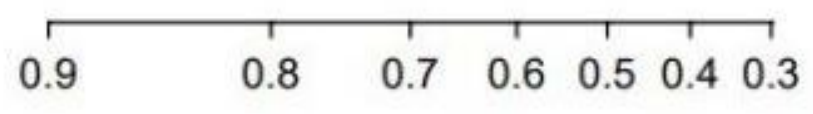

Figure 8

A nomogram for predicting the CSS survival rate of patients with EGC 

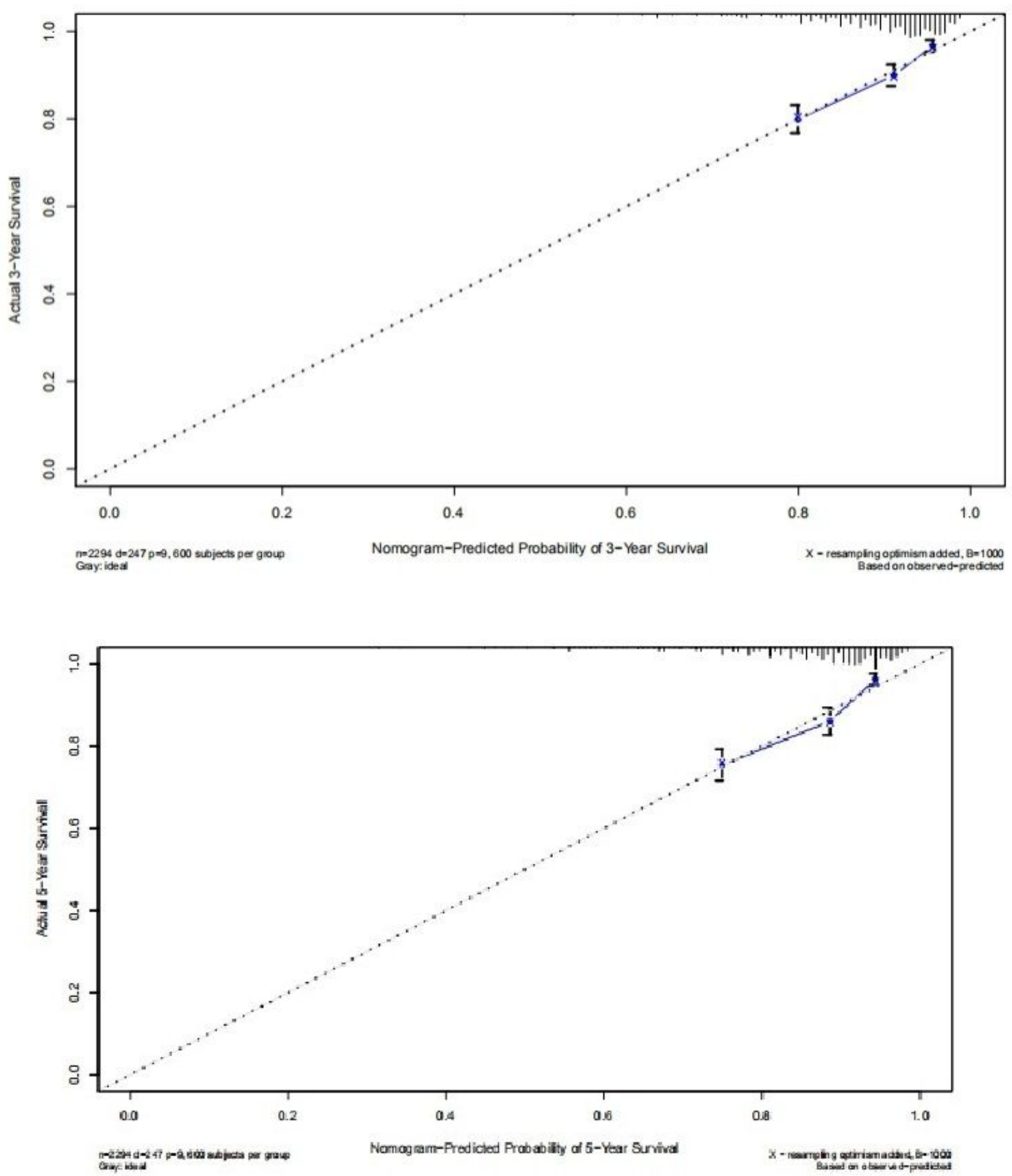

Figure 9

Correction chart of survival prediction model for patients with EGC 

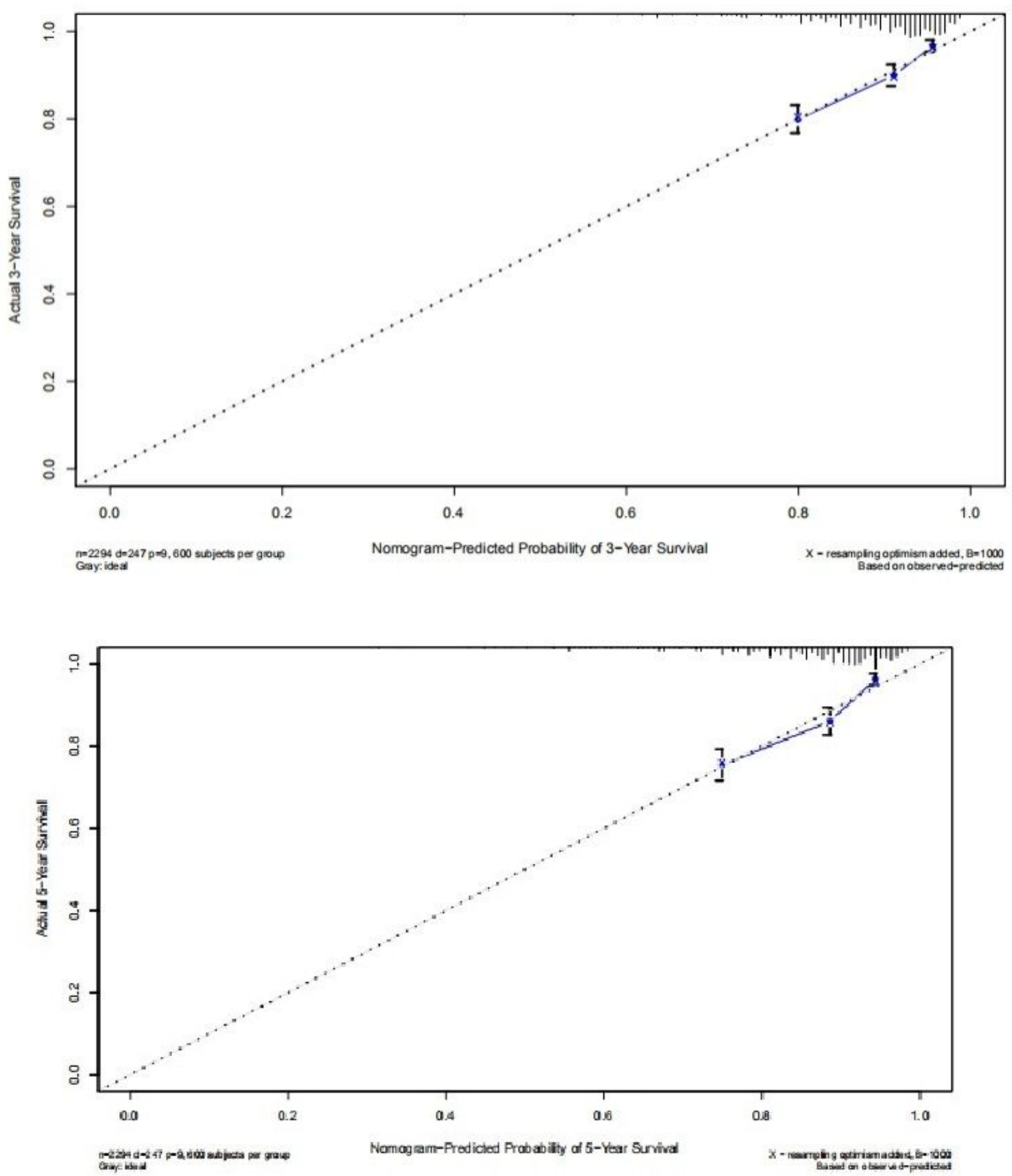

Figure 9

Correction chart of survival prediction model for patients with EGC 
3-year Survival AUC $=0.706$

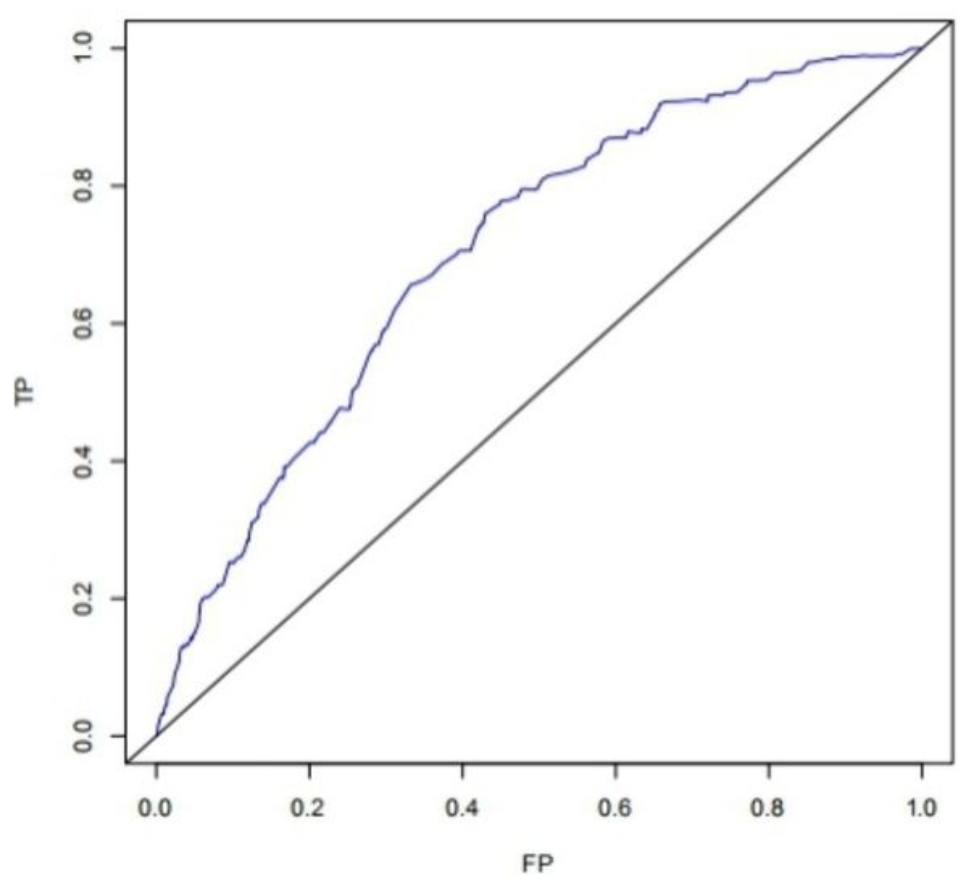

5-year Survival AUC $=0.71$

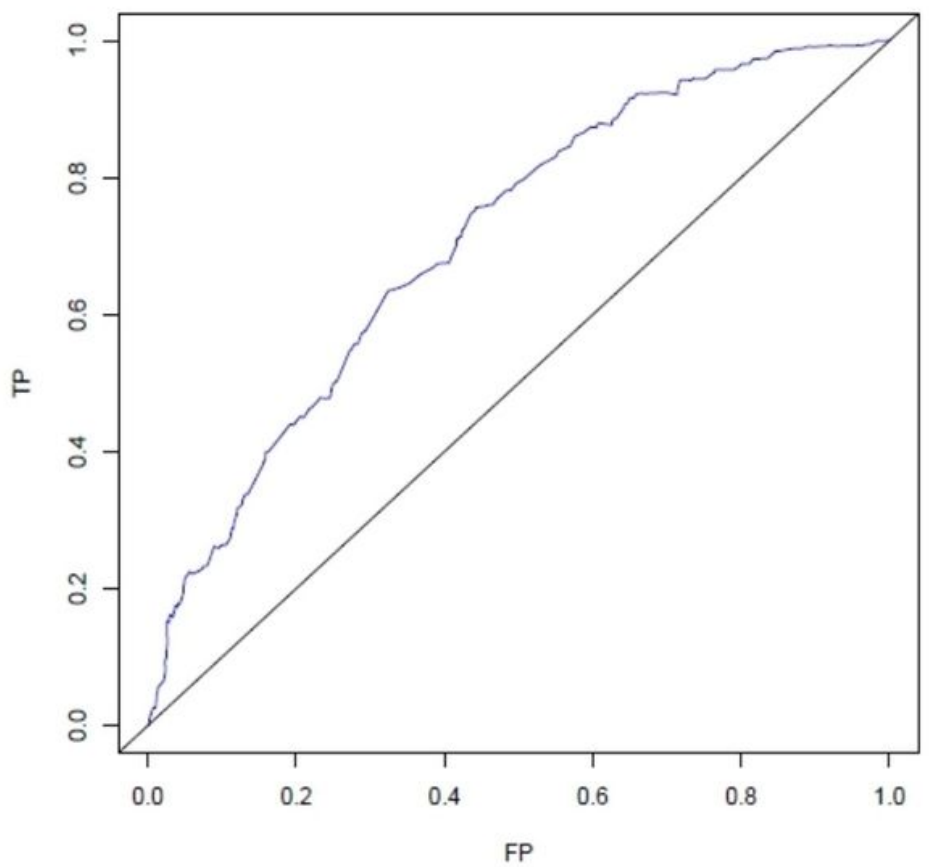

\section{Figure 10}

3-year and 5-year CSS survival rate ROC curve (After 1000 bootstraps, the 3-year survival rate AUC=0.706, and the 5-year survival rate $\mathrm{AUC}=0.710$ )

3-year Survival AUC $=0.706$

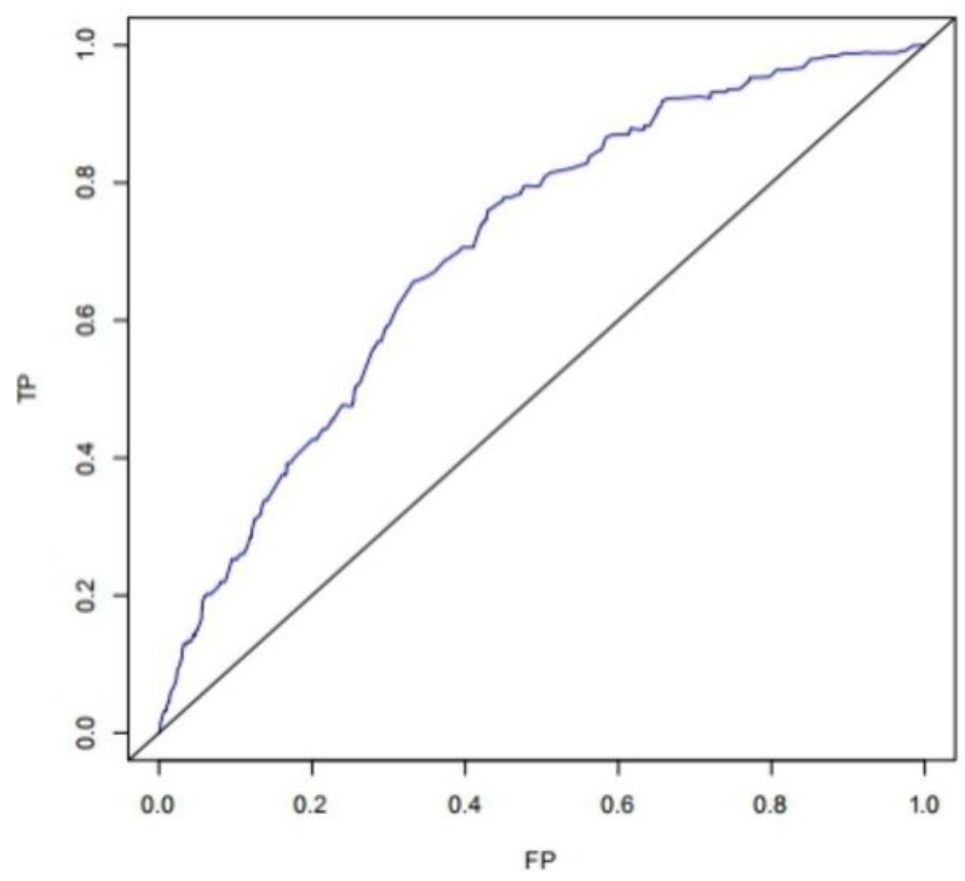

5-year Survival AUC $=0.71$

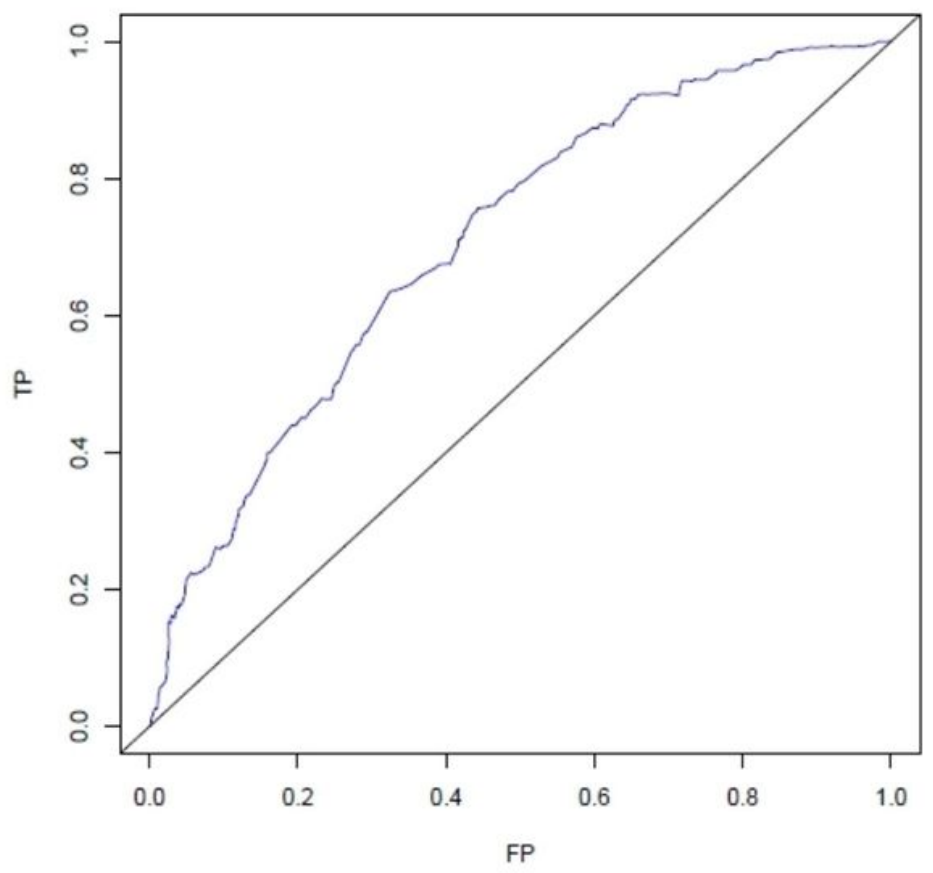

Figure 10 
3-year and 5-year CSS survival rate ROC curve (After 1000 bootstraps, the 3-year survival rate AUC=0.706, and the 5 -year survival rate $\mathrm{AUC}=0.710$ ) 